\title{
DETECÇÃO E CARACTERIZAÇÃO DA RESISTÊNCIA DE Brevipalpus phoenicis (GEIJSKES, 1939) (ACARI: TENUIPALPIDAE) AO ACARICIDA PROPARGITE
}

\section{CLÁUDIO ROBERTO FRANCO}

Dissertação apresentada à Escola Superior de Agricultura "Luiz de Queiroz", Universidade de São Paulo, para obtenção do título de Mestre em Ciências, Área de Concentração: Entomologia.

P I R A C I C A B A

Estado de São Paulo - Brasil

Dezembro - 2002 


\title{
DETECÇÃO E CARACTERIZAÇÃO DA RESISTÊNCIA DE Brevipalpus phoenicis (GEIJSKES, 1939) (ACARI: TENUIPALPIDAE) AO ACARICIDA PROPARGITE
}

\author{
CLÁUDIO ROBERTO FRANCO \\ ENGENHEIRO AGRÔNOMO
}

Orientador: Prof. Dr. CELSO OMOTO

Dissertação apresentada à Escola Superior de Agricultura "Luiz de Queiroz", Universidade de São Paulo, para obtenção do título de Mestre em Ciências, Área de Concentração: Entomologia.

P I R A C I C A B A

Estado de São Paulo - Brasil

Dezembro - 2002 


\section{Dados Internacionais de Catalogação na Publicação (CIP)} DIVISÃo DE BIBLIOTECA E DOCUMENTAÇÃO - ESALQ/USP

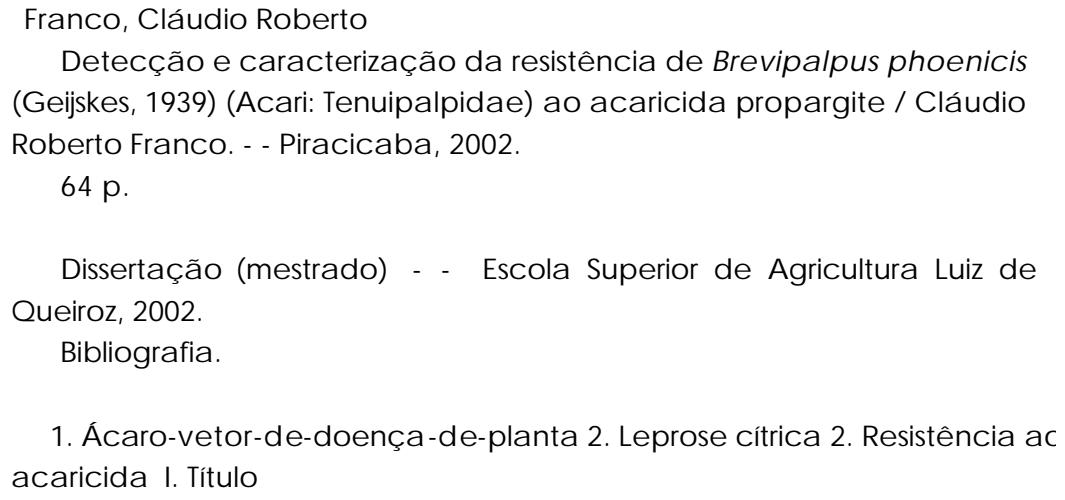

1. Ácaro-vetor-de-doença-de-planta 2. Leprose cítrica 2. Resistência ac acaricida I. Título

CDD 632.6542

"Permitida a cópia total ou parcial deste documento, desde que citada a fonte - $\mathrm{O}$ autor" 
Aos meus pais

Genésio e Vitória pelo amor, dedicação e exemplo

DEDICO ...

... Aos meus irmãos Valéria, Renato, Paulo e ao meu cunhado Abílio pelo apoio às minhas sobrinhas Caroline e Larissa pela alegria a minha companheira e amiga Sabrina pelo amor

AGRADEÇO. 


\section{AGRADECIMENTOS}

Ao Prof. Dr. Celso Omoto pela confiança, orientação e amizade transmitidas desde o curso de graduação e durante o Programa de Pós-graduação.

Aos professores do Programa de Pós-graduação em Entomologia da ESALQ pelos ensinamentos transmitidos que foram importantes na minha formação profissional e pessoal.

Ao Fundo Paulista de Defesa da Citricultura pela concessão da bolsa de estudo e pelo apoio financeiro para o desenvolvimento deste trabalho.

À Fischer Agropecuária S.A. e Guacho Agropecuária pelo fornecimento de material para execução do projeto.

Aos Prof. Dr. Silvio Sandoval Zocchi e Clarice Garcia Borges Demétrio pelo auxílio nas análises estatísticas.

Ao Manuel Javier Dieguez e ao Engenheiro Agrônomo Marcelo Imthon Gerlinger da Uniroyal Química Ltda pelo apoio na execução do projeto.

Aos Engenheiros Agrônomos e amigos Roberto Hiroyuki Konno, Everaldo Batista Alves, Fernando Joly Campos, Marcelo Polleti, Eloisa Salmeron, Marina Regina 
Frizzas, Ricardo Antonio Polanczyk e ao biólogo Jorge Anderson Guimarães pela amizade e companheirismo demonstrado ao longo da realização do trabalho.

Aos colegas do Programa de Pós-graduação e funcionários do Setor de Entomologia pela amizade e incentivo durante o desenvolvimento do projeto.

Aos estagiários Nádia Fernanda Bertan Casarin, Luis Fernando Gibeli e a todas as pessoas que direta ou indiretamente auxiliaram no desenvolvimento do projeto. 


\section{SUMÁRIO}

Página

LISTA DE FIGURAS.......................................................................... viii

LISTA DE TABELAS......................................................................... ix

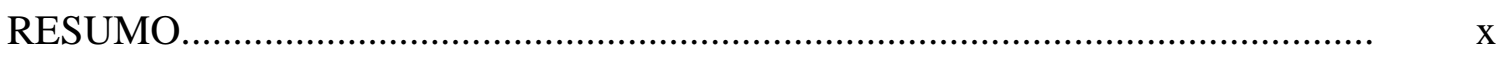

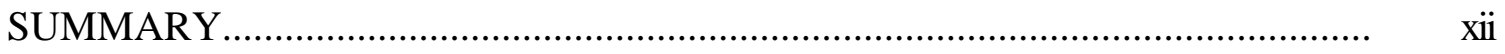

1 INTRODUÇÃÁ

2 REVISÃO DE LITERATURA.................................................................... 4

$2.1 \mathrm{O}$ ácaro-da-leprose Brevipalpus phoenicis.................................................... 4

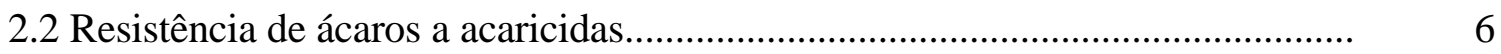

2.2.1 Resistência de ácaros ao propargite............................................................ 7

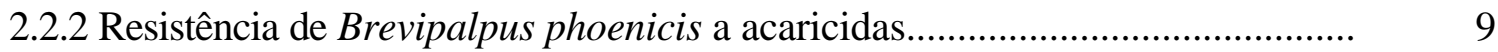

2.3 Fatores que afetam a evolução da resistência de Brevipalpus

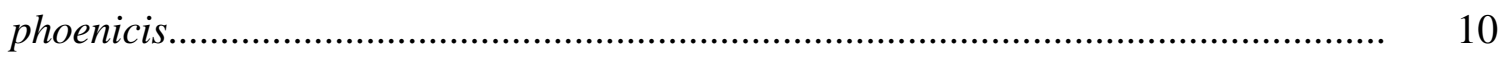

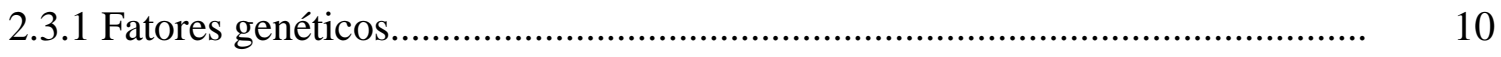

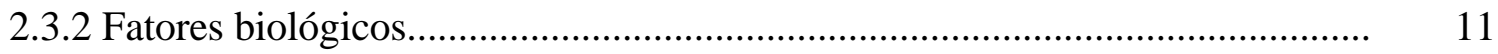

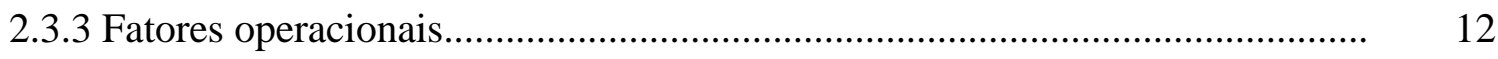

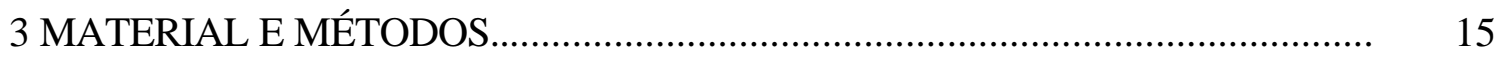

3.1 Coleta das populações de Brevipalpus phoenicis.............................................. 15

3.2 Criação de Brevipalpus phoenicis em laboratório............................................. 15

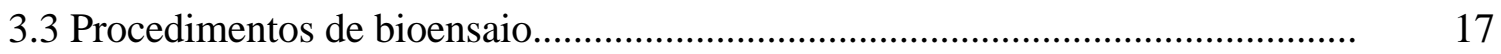


3.4 Caracterização da linha-básica de suscetibilidade de Brevipalpus phoenicis ao propargite.

3.5 Monitoramento da suscetibilidade das populações de Brevipalpus phoenicis ao propargite

3.6 Caracterização da resistência de Brevipalpus phoenicis ao propargite

3.7 Interação de Brevipalpus phoenicis, propargite e citros...................................... 20

3.7.1 Efeito do modo de exposição de Brevipalpus phoenicis ao propargite.

3.7.2 Persistência da atividade biológica de propargite sobre Brevipalpus phoenicis.

4 RESULTADOS E DISCUSSÃO..

4.1 Caracterização da linha-básica de suscetibilidade de Brevipalpus phoenicis ao propargite

4.2 Monitoramento da suscetibilidade das populações de Brevipalpus phoenicis ao propargite.

4.3 Caracterização da resistência de Brevipalpus phoenicis ao propargite.

4.4 Interação de Brevipalpus phoenicis, propargite e citros.

4.4.1 Efeito do modo de exposição de Brevipalpus phoenicis ao propargite.

4.4.2 Persistência da atividade biológica de propargite sobre Brevipalpus phoenicis.

4.5 Considerações finais.................................................................................... 42

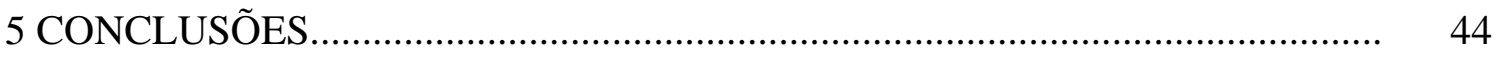

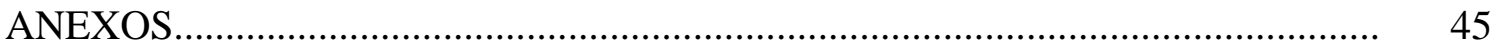

REFERÊNCIAS BIBLIOGRÁFICAS............................................................ 49 


\section{LISTA DE FIGURAS}

Página

1 Caracterização toxicológica da linhagem suscetível (S) de Brevipalpus phoenicis ao propargite para os períodos de exposição de 24 (•) e 48 horas (O)

2 Porcentagem de sobrevivência (erro padrão da média) de populações de Brevipalpus phoenicis ao propargite coletadas em diferentes pomares de citros do Estado de São Paulo nas concentrações diagnósticas de 320 (口) e 720 ( ) $\mu \mathrm{g}$ de propargite/ml de água

3 Caracterização da resistência de Brevipalpus phoenicis ao propargite. Nesta figura encontram-se representadas a linhagem suscetível $(\mathrm{S})(\bullet)$, população BAR-1 $(\diamond)$ e linhagem resistente $(\mathrm{R})(\mathrm{O})$

4 Caracterização toxicológica das linhagens suscetível $(\mathrm{S})(\bullet)$ e resistente $(\mathrm{R})$ (O) de Brevipalpus phoenicis ao propargite pelo contato residual (A) e contato direto $(\mathrm{B})$.

5 As curvas referem-se ao ajuste dos dados observados aos modelos logísticos linear e cúbico para as linhagens suscetível $(\mathrm{S})(\bullet)$ e resistente $(\mathrm{R})(\mathrm{O})$ de Brevipalpus phoenicis ao propargite para os períodos de exposição de 24 (A) e 48 horas (B) 


\section{LISTA DE TABELAS}

Página

1 Resultados da análise de Probit para a caracterização toxicológica da linhagem suscetível (S) de Brevipalpus phoenicis ao propargite com avaliação realizada 24 e 48 horas após a exposição.

2 Porcentagem média $(\uplus$ erro padrão da média) de sobrevivência das populações de Brevipalpus phoenicis coletadas em diferentes talhões de pomares comerciais de citros do Estado de São Paulo nas concentrações diagnósticas

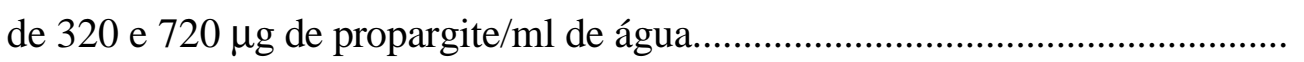

3 Resultados da análise de Probit para as caracterizações toxicológicas da linhagem suscetível (S), da população BAR-1 e da linhagem resistente $(\mathrm{R})$ de Brevipalpus phoenicis ao propargite.

4 Resultados da caracterização toxicológica da linhagem suscetível (S) e resistente (R) de Brevipalpus phoenicis ao propargite avaliada pelo bioensaio de contato residual e contato direto. 


\title{
DETECÇÃO E CARACTERIZAÇÃO DA RESISTÊNCIA DE Brevipalpus phoenicis (GEIJSKES, 1939) (ACARI: TENUIPALPIDAE) AO ACARICIDA PROPARGITE
}

\author{
Autor: CLÁUDIO ROBERTO FRANCO \\ Orientador: Prof. Dr. CELSO OMOTO
}

\section{RESUMO}

O ácaro-da-leprose Brevipalpus phoenicis (Geijskes) é uma das principais pragas da citricultura por ser o vetor do vírus causador da leprose dos citros. O acaricida propargite tem sido bastante utilizado no controle deste ácaro. Sendo assim, o objetivo deste trabalho foi o de coletar subsídios para a implementação de um programa de manejo da resistência de B. phoenicis ao propargite. Foram conduzidos trabalhos de caracterização da linha-básica de suscetibilidade de B. phoenicis ao propargite, monitoramento da suscetibilidade ao propargite em diferentes populações de $B$. phoenicis, caracterização da resistência de B. phoenicis ao propargite e avaliação da interação de B. phoenicis, propargite e citros. A técnica de bioensaio adotada foi o contato residual pulverizando discos de folhas de citros com o auxílio da Torre de Potter. As $\mathrm{CL}_{50}$ (IC 95\%) estimadas para as linhagens suscetível (S) e resistente (R) foram $217,51(207,07-228,35)$ e $2.195,43(1.759,23-2.808,21) \mu \mathrm{g}$ de propargite/ml de água [I.A. (ppm)] respectivamente. A razão de resistência foi de 10 vezes. As concentrações diagnósticas definidas para o monitoramento da suscetibilidade foram 320 e $720 \mu \mathrm{g}$ de propargite/ml de água [I.A. (ppm)]. Foram observadas diferenças significativas na 
suscetibilidade de populações do ácaro-da-leprose ao propargite. A partir da avaliação da interação de B. phoenicis, propargite e citros, verificou-se que o modo de exposição de ácaros por contato residual proporcionou maior discriminação entre as linhagens $\mathrm{S}$ e $\mathrm{R}$ do que por contato direto em condições laboratoriais. A persistência da atividade biológica de propargite sobre frutos de citros foi baixa em condições de campo e as linhagens $\mathrm{S}$ e $\mathrm{R}$ foram claramente discriminadas pelo resíduo de propargite, sugerindo que a evolução da resistência pode se processar principalmente pelo contato residual de B. phoenicis sobre o propargite. 


\title{
DETECTION AND CHARACTERIZATION OF Brevipalpus phoenicis (GEIJSKES, 1939) (ACARI: TENUIPALPIDAE) RESISTANCE TO THE ACARICIDE PROPARGITE
}

\author{
Author: CLÁUDIO ROBERTO FRANCO \\ Adviser: Prof. Dr. CELSO OMOTO
}

\section{SUMMARY}

The citrus flat mite Brevipalpus phoenicis (Geijskes) is one of the most important citrus pests because it vectors the citrus leprosis virus. The acaricide propargite has been frequently used to control this mite. Therefore, the objective of this work was to collect basic information for implementing a resistance management program of B. phoenicis to propargite. In this work it was conducted studies on baseline susceptibility of $B$. phoenicis to propargite, monitoring the susceptibility to propargite in different $B$. phoenicis populations, characterization of propargite resistance in $B$. phoenicis and evaluation of interaction of B. phoenicis, propargite and citrus. The bioassay technique used in this study was the residual contact with the use of citrus leaf disks sprayed with the Potter spray tower. The estimated $\mathrm{LC}_{50}(95 \% \mathrm{CI})$ to susceptible (S) and resistant (R) strains were 217.51 (207.07-228.35) and 2,195.43 (1,759.23$2,808.21) \mu \mathrm{g}$ of propargite/ml of water [A.I. (ppm)], respectively. The resistance ratio was 10-fold. The diagnostic concentrations defined for monitoring the resistance were 320 and $720 \mu \mathrm{g}$ of propargite/ml of water [A.I. (ppm)]. A significant difference in susceptibility to propargite was detected in B. phoenicis populations. Studies on 
evaluation of interaction of $B$. phoenicis, propargite and citrus revealed that the mode of exposure of mites by residual contact gave better discrimination between $\mathrm{S}$ and $\mathrm{R}$ strains than by direct contact under laboratory conditions. The persistence of biological activity of propargite on citrus fruit was low under field conditions and there was a clear discrimination between $\mathrm{S}$ and $\mathrm{R}$ strain on propargite residues, suggesting that the evolution of resistance can be processed mainly by the residual contact of B. phoenicis on propargite. 


\section{INTRODUÇÃO}

O Estado de São Paulo é responsável por mais de $80 \%$ da produção brasileira de citros (FNP Consultoria \& Comércio, 2002; Neves et al., 2001a). Entretanto, vários fatores contribuem para a instabilidade da produção, entre eles os fitossanitários. O ácaro-da-leprose Brevipalpus phoenicis (Geijskes) é considerado uma das principais pragas da citricultura brasileira por ser o vetor do vírus causador da leprose dos citros (Chiavegato, 1987; Guirado \& Silverio, 1992; Kitajima et al., 1972; Rodrigues et al., 2001). O controle químico tem sido o principal método de controle empregado para manter esta praga abaixo do nível de dano econômico (Comenale Neto et al., 1995; Sato \& Raga, 1998). Anualmente, são gastos aproximadamente 90 milhões de dólares, sendo que mais de $80 \%$ desse valor são destinados ao combate do ácaro-da-leprose (Neves et al., 2001b; Salvo Filho, 1997). Nos últimos anos vem sendo observado menor eficiência de alguns acaricidas utilizados no controle de B. phoenicis. Diversos fatores podem contribuir para redução da eficácia no controle, entre eles, a resistência de pragas a pesticidas (Omoto, 1995).

Como consequiências da evolução da resistência, freqüentemente, a primeira resposta dos agricultores tem sido o aumento da dose aplicada, seguido pelo aumento no número de aplicações e por fim a substituição por outro pesticida, geralmente de maior toxicidade e custo. A adoção destas medidas de controle representam uma solução momentânea, já que com o decorrer do tempo a resistência pode se desenvolver para todos os produtos, comprometendo os programas de Manejo Integrado de Pragas (MIP) (Georghiou, 1986). 
A resistência de $B$. phoenicis a acaricidas foi inicialmente questionada na safra de 1974/75 (Myazaki et al., 1982; Suplicy Filho et al., 1977). Recentemente, a evolução da resistência do ácaro-da-leprose foi detectada para o dicofol (Omoto et al., 2000) e hexitiazox (Campos \& Omoto, 2002). Entretanto, para os acaricidas organoestânicos como óxido de fembutatina e cihexatina não foram observadas diferenças na suscetibilidade nas populações do ácaro-da-leprose (Konno et al.; 2001).

Os acaricidas organoestânicos, dicofol, hexitiazox e propargite são os principais produtos utilizados na citricultura (Nakano, 1995). Em 2000, o propargite foi utilizado em $8 \%$ dos pomares citrícolas tratados com acaricidas em São Paulo $\left(\right.$ COOPERCITRUS $\left.^{1}\right)$. O propargite apresenta algumas vantagens para programas de MIP como ausência de resistência cruzada com o dicofol (Alves et al., 2000a), baixa persistência em campo (Pree et al., 1992) e baixa toxicidade para insetos (Ware, 1991). Associado à dificuldade e ao alto custo para descoberta de uma nova molécula de um pesticida, torna-se importante a realização de estudos ligados à resistência para a implementação de estratégias efetivas para prevenir e/ou retardar o desenvolvimento da resistência de $B$. phoenicis ao propargite e dessa forma prolongar sua vida útil.

A evolução da resistência de ácaros ao propargite já foi confirmada na Austrália para Tetranychus urticae Koch em maçã (Unwin, 1973) e em rosa (Goodwin et al., 1995), no Israel para Tetranychus cinnabarinus (Boisduval) em rosa (Mansour \& Plaut, 1979), na Nova Zelândia para T. urticae e Panonychus ulmi (Koch) nas culturas da groselha preta e maçã respectivamente (Chapman \& Penman, 1984), nos Estados Unidos para T. urticae e Tetranychus pacificus McGregor na cultura da amêndoa (Keena \& Granett, 1985; 1987) e algodão (Dennehy et al., 1987; Grafton-Cardwell et al., 1987), na China para Tetranychus viennensis Zacher em maçã (Shen, 1999) e no Brasil para T. urticae em rosa (Suplicy Filho et al., 1994; Takematsu et al., 1994), videira (Souza Filho et al., 1994) e morango (Sato et al., 1994a; Sato \& Silva, 2002). Portanto este trabalho teve como objetivos estabelecer a linha-básica de suscetibilidade de B. phoenicis ao propargite, avaliar a suscetibilidade ao propargite em diferentes populações do ácaro-da-

\footnotetext{
${ }^{1}$ COOPERCITRUS (Cooperativa dos Cafeicultores e Citricultores de São Paulo). Comunicação pessoal, 2001.
} 
leprose coletadas em pomares de citros do Estado de São Paulo, detectar e caracterizar a resistência de $B$. phoenicis ao propargite e estudar a interação de B. phoenicis, propargite e citros. 


\section{REVISÃO DE LITERATURA}

\subsection{O ácaro-da-leprose Brevipalpus phoenicis}

O ácaro-da-leprose Brevipalpus phoenicis (Geijskes) é uma espécie polífaga e apresenta distribuição cosmopolita, tendo sido encontrado na África, Ásia, Austrália, Europa, América do Norte, América do Sul e Ilhas do Pacífico (Haramoto, 1969). Segundo Pritchard \& Baker citado por Childers et al. (2001), até 1958 tinham sido descritas 63 plantas hospedeiras. Atualmente, segundo Ochoa et al. citado por Childers et al. (2001), na América Central foram descritas 114 plantas hospedeiras de $B$. phoenicis. No Brasil, a presença de B. phoenicis em citros foi confirmada em 1959 (Rossetti et al., 1959). Segundo Trindade \& Chiavegato (1994) o ácaro-da-leprose foi encontrado em 34 espécies de plantas cultivadas, ornamentais e invasoras em pomares cítricos de várias localidades do Estado de São Paulo.

No Brasil, além de estar associado à transmissão do vírus da leprose (Kitajima et al., 1972; Musumecci \& Rossetti, 1963; Rodrigues et al., 1997) e da clorose zonada em citros (Rossetti et al., 1965) também é importante vetor de outras doenças como a mancha anular do cafeeiro (Chagas, 1973), a pinta verde no maracujá amarelo (Kitajima et al., 1997), a mancha anular no Ligustrum lucidum L. (Rodrigues \& Nogueira, 1996) e em outras plantas ornamentais (Childers et al., 2001).

O ciclo biológico do ácaro-da-leprose é constituído pelas fases de ovo, larva, protoninfa, deutoninfa e adulto, sendo que entre cada ínstar ocorrem períodos de imobilidade chamados de protocrisálida, deutocrisálida e teliocrisálida (Flechtmann, 1977; Haramoto, 1969). A postura é realizada em locais protegidos, como em frestas na 
superfície de plantas. Os ovos são colocados individualmente, entretanto, é comum verificar a presença de ovos agrupados (Haramoto, 1969; Lal, 1978). Haramoto (1969) estudou em laboratório o ciclo de vida de B. phoenicis em frutos de mamoeiro em diferentes condições de umidade e temperatura. O desenvolvimento do ácaro-da-leprose nas faixas de umidade de 65 a $70 \%$ e 85 a $90 \%$ foram semelhantes, enquanto na umidade de 25 a $30 \%$ houve redução superior a $90 \%$ na viabilidade de ovos e prolongamento do período de incubação. Nas temperaturas de 20,25 e $30{ }^{\circ} \mathrm{C}$ e umidade de 65 a $70 \%$ o período de incubação foi de 22,2; 9,4 e 8,2 dias, o período de ovo a adulto de 48,8; 29,3 e 18,6 dias, a longevidade de 45,8; 34,8 e 10,5 dias e a fecundidade de 10,6; 57,5 e 6,4 ovos respectivamente.

Chiavegato (1986) estudou a biologia de B. phoenicis utilizando frutos e folhas de laranja da variedade Pera Rio e observou que o período de ovo a adulto foi mais rápido em frutos do que em folhas à $30{ }^{\circ} \mathrm{C}$ com valores de 14,37 e 17,62 dias respectivamente. $\mathrm{O}$ desenvolvimento em frutos na temperatura de $20{ }^{\circ} \mathrm{C}$ foi de 43,47 dias. O número de ovos em frutos à 30 e $20{ }^{\circ} \mathrm{C}$ foi de 39,17 e 8,57 ovos, respectivamente, enquanto em folhas à $30{ }^{\circ} \mathrm{C}$ foi de 8,57 ovos. Em trabalho conduzido em condições de campo por Oliveira (1986) revelaram que a infestação média do ácaroda-leprose em folhas novas, folhas velhas e frutos foi de 0,56; 4,28 e 95,19\% respectivamente.

As diferentes plantas cítricas podem influenciar no desenvolvimento do ácaroda-leprose. Chiavegato \& Mischan (1987) observaram que frutos das variedades Valência e Murcote foram mais favoráveis ao desenvolvimento do ácaro do que o Limão Taiti e Siciliano e Lima da Pérsia. Trindade \& Chiavegato (1990) verificaram que as variedades Natal, Valência e Pera Rio foram as mais favoráveis ao desenvolvimento de B. phoenicis do que as variedades Ponkan, Limão Cravo, Laranja Azeda e Cleópatra, sendo esta última a menos favorável. 


\subsection{Resistência de ácaros a acaricidas}

A Organização Mundial de Saúde citado por Croft \& Van de Bann (1988) define a resistência como "o desenvolvimento da habilidade em uma população em tolerar doses de um tóxico que seriam letais para a maioria dos indivíduos de uma população normal da mesma espécie". A resistência aos pesticidas é um exemplo de mudanças evolucionárias onde o pesticida atua como o agente seletivo de indivíduos resistentes que estão em baixa frequiência na população original (Crow, 1957).

O primeiro relato de resistência de ácaros a acaricidas foi em 1937 para uma população de Tetranychus telarius L. resistente a um composto à base de selênio $\left(\right.$ Selocide $\left.^{\circledR}\right)$ (Compton \& Kearns, 1937). Porém, somente a partir da utilização dos inseticidas sintéticos com o uso do DDT em 1939, houve um aumento rápido nos casos de resistência. Segundo Georghiou \& Tejeda (1991), foram documentadas 504 espécies entre ácaros e insetos resistentes a pesticidas. $\mathrm{O}$ maior número de casos foram observados para pragas de importância agrícola com 56,1\% e os ácaros representam $14,1 \%$ dos casos documentados.

Segundo Georghiou \& Mellon (1983) foram observados casos de resistência nas principais famílias de ácaros de importância agrícola (Eriophyidae, Tenuipalpidae e Tetranychidae) para praticamente todos os grupos químicos de produtos, entre eles o DDT, ciclodienos, fosforados, carbamatos e organosulfurados (propargite). A resistência também tem sido documentada para os produtos de uso relativamente mais recentes como hexitiazox e clofentezina (Welty et al., 1989), flucicloxurom (Grosscurt et al., 1994), piretróides (Herron et al., 2001), organoestânicos (Hoy et al., 1988; Hoyt et al., 1985), piridabem, fempiroximate, tebufenpirade (Stumpf \& Nauen, 2001).

No Brasil, foram realizados trabalhos de detecção da resistência em $B$. phoenicis ao dicofol (Omoto et al., 2000), organoestânicos (Konno et al., 2001) e hexitiazox (Campos \& Omoto, 2002), Tetranychus urticae Koch ao propargite (Sato \& Silva, 2002; Sato et al., 1994a; Souza Filho et al., 1994; Suplicy Filho et al., 1994; Takematsu et al., 1994) e para os ácaros predadores Euseius concordis (Chant) e Iphiseiodes zuluagai Denmark \& Muma ao dicofol e deltametrina (Poletti, 2002). 


\subsubsection{Resistência de ácaros ao propargite}

O acaricida propargite vem sendo utilizado no controle de ácaros desde da década de 70 (Jeppson et al., 1969; Keena \& Granett, 1987). Na citricultura brasileira teve o seu uso regulamentado no final da década de 80, sendo recomendado para o controle de B. phoenicis, Phyllocoptruta oleivora (Ashmead) e Panonychus citri (McGregor). $\mathrm{O}$ propargite pertence ao grupo químico sulfito de alquila (fenoxiciclohexil, organosulfurado), fórmula química $\mathrm{C}_{19} \mathrm{H}_{26} \mathrm{O}_{4} \mathrm{~S}$.

Os primeiros compostos que atuam na inibição da respiração celular foram descobertos no final do século XIX, entretanto sua participação na história dos pesticidas sintéticos é recente. Por essa razão são importantes pesticidas para o manejo da resistência (Casida \& Quistad, 1998). A respiração celular é realizada por meio de inúmeras etapas no interior das mitocôndrias e sua inibição irá comprometer a formação de ATP e outros substratos intermediários necessários para as reações bioquímicas. Os inibidores da respiração celular atuam no transporte de elétrons e fosforilação oxidativa (Corbett et al., 1984).

Segundo Corbett et al. (1984), os acaricidas que contém enxofre nas suas moléculas, como o clorfensom e tetradifom, provavelmente apresentam a ATPase mitocondrial como sítio de ação. Em trabalho realizado por Kadir \& Knowles (1991), os compostos propargite, cloropropilato, bromopropilato, oxitioquinox, cihexatina, ovex, clorbenside e flubenzimine causaram inibição superior a $80 \%$ da atividade da ATPase$\mathrm{Mg}^{2+}$ do ácaro Rhizoglyphus echinopus (Fumouze \& Robin). Portanto os autores sugerem que a inibição dessa enzima seja um importante mecanismo de ação desses pesticidas.

O primeiro relato de resistência de ácaros ao propargite ocorreu na Austrália em pomares de maçãs. Foram observadas populações de T. urticae com baixa razão de resistência, entre 2,0 e 3,6 vezes, utilizando método de bioensaio residual (Unwin, 1973). Em rosas foram observadas populações de T. urticae que apresentavam razão de resistência entre 3,9 e 135,0 vezes ao acaricida propargite, utilizando o método de bioensaio de contato direto (Goodwin et al., 1995). 
Em Israel foi coletada uma linhagem de Tetranychus cinnabarinus (Boisduval) em rosas que apresentou alta razão de resistência para os acaricidas dicofol e bromopropilato (166,7 e 24,4 vezes respectivamente) e baixa razão de resistência para o propargite e cihexatina (5,3 e 2,5 vezes respectivamente), utilizando método de bioensaio de contato direto por imersão (Mansour \& Plaut, 1979).

$\mathrm{Na}$ cultura da groselha preta e em maçã na Nova Zelândia foram detectadas uma linhagem de T. urticae e Panonychus ulmi (Koch) resistente ao propargite com razões de resistência de 5,2 e 6,8 vezes respectivamente, utilizando método de bioensaio de contato direto por imersão e residual respectivamente (Chapman \& Penman, 1984).

Nos Estados Unidos foi verificada significativa variabilidade na suscetibilidade entre populações de Tetranychus pacificus McGregor ao propargite, sendo detectada uma população com razão de resistência de 23,7 vezes e entre populações de $T$. urticae a razão de resistência foi de 42,6 vezes na cultura da amêndoa, utilizando bioensaio residual com imersão de folhas (Keena \& Granett, 1985, 1987).

Na cultura do algodão, na Califórnia, Estados Unidos, Grafton-Cardwell et al. (1987) relacionaram a magnitude da resistência com as concentrações utilizadas em campo de 3.162 a $10.000 \mu \mathrm{g}$ de propargite/ml de água [I.A. (ppm)]. Foram observadas 100\% de mortalidade em populações de Tetranychus turkestani Ugarov \& Nkolski a partir da concentração de $562 \mu \mathrm{g}$ de propargite/ml de água [I.A. (ppm)]. Baixo nível de resistência foram observados em $10 \%$ das populações coletadas de T. urticae com 100\% mortalidade em concentrações a partir de $1.780 \mu \mathrm{g}$ de propargite/ml de água [I.A. (ppm)] e 19\% apresentaram alto nível de resistência com sobreviventes nas concentrações de 3.162 e $5.162 \mu \mathrm{g}$ de propargite/ml de água [I.A. (ppm)]. Em nenhuma população de $T$. pacificus foi verificada mortalidade na concentração de $562 \mu \mathrm{g}$ de propargite/ml de água [I.A. (ppm)] utilizando bioensaio residual com imersão de folhas, sendo confirmado a maior tolerância de $T$. pacificus ao propargite comparado a $T$. urticae e T. turkestani. Segundo Dennehy et al. (1987), T. urticae apresentou razão de resistência de 41,59 vezes e uma linhagem de T. urticae resistente ao dicofol com razão de resistência superior a 500 vezes apresentou razão de resistência de 26,46 vezes ao propargite, utilizando método de bioensaio residual. Grafton-Cardwell et al. (1987) 
verificaram que apenas 9 e $16 \%$ das áreas infestadas com T. urticae e T. pacificus foram resistentes ao propargite e dicofol, sugerindo como sendo um caso de resistência múltipla ao invés de resistência cruzada.

Shen (1999) estudando a resistência de Tetranychus viennensis Zacher a diversos acaricidas em maçã na China, verificou que a partir de uma população desse ácaro foi possível a obtenção de uma população com razão de resistência de aproximadamente 130 vezes após 15 aplicações de propargite, em condições de laboratório, com uma concentração que proporcionava mortalidade entre 50 e $60 \%$. A população selecionada se mostrou também resistente ao quinalfos com razão de resistência de 6,7 vezes, utilizando o método de bioensaio de contato direto por imersão.

Trabalhos realizados no Brasil para verificar a suscetibilidade de populações de T. urticae provenientes de roseira em Itapevi e Holambra, videira em Pilar do Sul e em morangueiro dos municípios de Atibaia e Piedade do Estado de São Paulo demonstraram baixa razão de resistência para o propargite, ou seja, de 1,24 a 2,43 vezes, utilizando método de bioensaio de contato direto por imersão (Sato et al., 1994a; Souza Filho et al., 1994; Suplicy Filho et al., 1994; Takematsu et al., 1994). No entanto, Sato \& Silva (2002) selecionaram uma linhagem para resistência com razão de resistência de 72,5 vezes, a partir de uma população de $T$. urticae proveniente de uma área comercial de morango.

\subsubsection{Resistência de Brevipalpus phoenicis a acaricidas}

A evolução da resistência do ácaro-da-leprose foi confirmada para os acaricidas dicofol e hexitiazox. Embora os acaricidas organoestânicos sejam muito utilizados na citricultura não foram observadas diferenças na suscetibilidade ao óxido de fembutatina e cihexatina em populações coletadas em diferentes pomares comerciais de citros (Konno et al., 2001).

Omoto et al. (2000) verificaram diferenças na suscetibilidade ao dicofol em

populações de $B$. phoenicis coletadas em diferentes pomares comerciais de citros do Estado de São Paulo. A linhagem resistente ao dicofol apresentou razão de resistência 
de 56,82 vezes. Foi verificado resistência cruzada positiva de dicofol com o bromopropilato, resistência cruzada negativa com o fempiroximate e ausência de resistência cruzada com óxido de fembutatina e propargite (Alves et al., 2000a). A resistência do ácaro-da-leprose ao dicofol foi instável ao longo de seis meses em condições laboratoriais. A instabilidade da resistência foi associada ao custo adaptativo apresentado pela linhagem resistente. A longevidade, período de oviposição e número de ovos por fêmea da linhagem suscetível foi de 31,41 e 25,57 dias e 30,70 ovos respectivamente e para a linhagem resistente foi de 21,73 e 15,02 dias e 15,81 ovos respectivamente (Alves, 1999).

A razão de resistência de $B$. phoenicis detectada para o hexitiazox foi superior a 10.000 vezes. As concentrações discriminatórias definidas para um programa de monitoramento da suscetibilidade ao hexitiazox foram 10 e $18 \mu \mathrm{g}$ de hexitiazox / $\mathrm{ml}$ de água [I.A. (ppm)] e revelaram diferenças significativas na suscetibilidade de populações

a esse acaricida. A resistência ao hexitiazox foi estável ao longo de seis meses em condições laboratoriais (Campos \& Omoto, 2002).

\subsection{Fatores que afetam a evolução da resistência de Brevipalpus phoenicis}

O processo de seleção é determinante para a evolução da resistência a pesticidas, sendo que a velocidade de desenvolvimento da resistência não é semelhante para todos os organismos. O conhecimento dos fatores que influenciam o processo de seleção é fundamental para o entendimento da evolução da resistência. Esses fatores podem ser divididos em três grupos: genéticos, biológicos e operacionais (Georghiou \& Taylor, 1977ab).

\subsubsection{Fatores genéticos}

Os fatores genéticos são referidos como a freqüência inicial do alelo resistente na população, número e dominância do alelo resistente e custo adaptativo dos indivíduos resistentes. No início da evolução da resistência, a frequência dos alelos resistentes na 
composição genética da população de um organismo está em baixa frequiência, sendo estimado entre $10^{-2}$ e $10^{-13}$ (Georghiou \& Taylor, 1977a; Roush \& McKenzie, 1987).

O ácaro-da-leprose é haplóide com dois cromossomos não-homólogos (n=2) (Helle et al., 1980; Pijnacker et al., 1980; Weeks et al., 2001). Além do histórico de aplicação de pesticidas (Georghiou \& Taylor, 1977a, 1986), o reduzido número de cromossomos no ácaro-da-leprose, associado a partenogênese telítoca, aumentam a chance de resistência múltipla, isto é, a presença de genes que conferem resistência a mais de um grupo químico de acaricidas, portanto, teoricamente, a evolução da resistência para B. phoenicis pode ser acelerada (Omoto, 1998).

Os indivíduos resistentes na ausência de pressão de seleção apresentam um custo adaptativo comparado aos indivíduos suscetíveis, geralmente relacionado a parâmetros biológicos, como por exemplo no tempo de desenvolvimento, fecundidade e fertilidade, caso contrário os indivíduos resistentes seriam mais comuns antes do processo de seleção (Crow, 1957; Georghiou \& Taylor, 1977a; Roush \& Croft, 1986; Roush \& McKenzie, 1987). A ocorrência de menor valor adaptativo da linhagem resistente associada à imigração de indivíduos suscetíveis permite o restabelecimento da suscetibilidade na ausência de pressão de seleção.

\subsubsection{Fatores biológicos}

Os principais fatores biológicos envolvidos na evolução da resistência são número de gerações por ano, número de descendentes, modo de reprodução, hábito alimentar (monófago ou polífago) e capacidade de dispersão (Georghiou \& Taylor, 1977a, 1986).

O modo de reprodução do ácaro-da-leprose é, principalmente, por partenogênese telítoca do tipo automítica, portanto, todos os descendentes de uma progenitora resistente serão resistentes e esse fato pode acelerar a evolução da resistência. Entretanto, segundo Haramoto (1969) este modo de reprodução pode contribuir para redução da variabilidade genética da população e associado à baixa freqüência de aplicação de acaricidas pode retardar a evolução da resistência. A 
ocorrência de machos na população de $B$. phoenicis é baixa e recentemente Weeks et al. (2001) relacionaram a presença de uma bactéria endosimbionte como responsável pela feminização do macho.

O hábito alimentar polífago pode retardar o desenvolvimento da resistência porque os ácaros que estão em plantas hospedeiras não pulverizadas (refúgio) podem imigrar para áreas tratadas, proporcionado a diluição da resistência pela infestação com ácaros suscetíveis. Entretanto, sob o ponto de vista bioquímico, a evolução da resistência pode ser acelerada para insetos polífagos porque podem apresentar maior atividade metabólica do que os monófagos (Georghiou \& Taylor, 1986).

O potencial reprodutivo de uma espécie apresenta relação positiva com a resistência, isto é, o desenvolvimento da resistência tende a ser mais rápido para espécies que apresentam alto potencial reprodutivo, pois um maior número de descendentes estarão sofrendo pressão de seleção (Georghiou \& Taylor, 1977a, 1986). O ácaro-daleprose está presente o ano todo, porém períodos de baixa precipitação favorecem o crescimento populacional. No Estado de São Paulo, o nível populacional aumenta a partir dos meses de março a abril, o que corresponde à época de diminuição da precipitação, atingindo níveis altos a partir de julho, com o pico populacional nos meses de setembro a outubro, para depois decrescer com o início das chuvas nos meses de novembro a dezembro (Oliveira, 1986; 1995).

\subsubsection{Fatores operacionais}

Os fatores operacionais podem ser divididos em dois grupos: (a) relacionados ao produto químico como, por exemplo, grupo químico, persistência e formulação; (b) as características da aplicação como, por exemplo, nível de controle, modo e estratégia de aplicação, estágio de desenvolvimento da praga e frequiência de aplicação (Georghiou \& Taylor, 1977ab).

A persistência do resíduo do pesticida exerce papel fundamental no desenvolvimento da resistência. A pressão de seleção é mais intensa para compostos com alta persistência (Georghiou \& Taylor, 1977a, 1986; Taylor \& Georghiou, 1982). 
Segundo Taylor \& Georghiou (1982), compostos que apresentam meia-vida de um dia o tempo necessário para a evolução da resistência em Culex quinquefasciatus Say é maior do que para compostos com meia-vida de dez dias. A aplicação de um pesticida pode inicialmente causar a mortalidade de todos os indivíduos, mas se a degradação do produto for lenta, provavelmente ocorrerá discriminação entre os indivíduos suscetíveis e resistentes. $\mathrm{O}$ uso da mistura de produtos consiste em uma importante estratégia utilizada em programas de manejo da resistência, sendo a persistência semelhante para ambos os pesticidas um dos requisitos para o sucesso da mistura (Roush, 1989).

Os pesticidas seletivos podem retardar o desenvolvimento da resistência devido à sobrevivência dos inimigos naturais que podem contribuir para eliminação de indivíduos resistentes, reduzindo a necessidade do uso de pesticidas (Roush, 1989). Os principais inimigos naturais associados ao ácaro-da-leprose encontrados em citros são os ácaros fitoseídeos I. zuluagai, Euseius citrifolius Denmark \& Muma e E. concordis (Chant). (Sato et al., 1994b). Poucos pesticidas utilizados foram seletivos a I. zuluagai e Euseius alatus DeLeon, inclusive o propargite, em condições laboratoriais (Reis et al., 1998, 1999). Resultados semelhantes foram observados em condições de campo onde o restabelecimento da população de ácaros predadores ocorreu somente após 120 dias para óxido de fembutatina e propargite e 147 dias para bromopropilato e fempropatrina (Sato et al., 1994c). A toxicidade residual da abamectina, fempiroximate, bifentrina, fempropatrina, propargite e cihexatina para I. zuluagai no $10^{\circ}$ dia após aplicação foi de $0 ; 21,6 ; 100 ; 100 ; 51,3$ e 16,2\% de mortalidade, respectivamente, sendo superior a 75\% para bifentrina até o 31ํㅡㅁ dia após aplicação (Sato et al., 1996). Embora o acaricida hexitiazox tenha apresentado baixa toxicidade aos ácaros predadores em citros (Raga et al., 1996, 1997; Sato et al., 1992, 1995) a resistência em B. phoenicis foi recentemente detectada por Campos \& Omoto (2002).

Dentre os fatores que influenciam a evolução da resistência, apenas os fatores operacionais podem ser manipulados pelo homem. Os fatores genéticos e biológicos não podem ser controlados e, geralmente, sua importância só pode ser estudada após o desenvolvimento da resistência. Por essa razão estudos para definir a melhor estratégia 
de uso dos acaricidas, seja em rotação ou em mistura, devem ser realizados para implementação de um programa de manejo da resistência de B. phoenicis a acaricidas. 


\section{MATERIAL E MÉTODOS}

O presente trabalho foi realizado no "Laboratório de Resistência de Artrópodes a Pesticidas" do Departamento de Entomologia, Fitopatologia e Zoologia Agrícola da Escola Superior de Agricultura "Luiz de Queiroz", Universidade de São Paulo, Piracicaba, Estado de São Paulo, no período de fevereiro de 2001 a dezembro de 2002.

\subsection{Coleta das populações de Brevipalpus phoenicis}

As populações de Brevipalpus phoenicis (Geijskes) foram coletadas em diferentes talhões de pomares comerciais de citros do Estado de São Paulo (Quadro 1). Aproximadamente 50 frutos infestados com o ácaro-da-leprose foram coletados de cada talhão e acondicionados em caixas de papelão ou de isopor e levadas ao laboratório.

No laboratório, foram transferidos de 120 a 160 ácaros adultos por fruto com auxílio de um pincel com um pêlo e um microscópio estereoscópico. O número inicial de ácaros de cada população foi de aproximadamente 600 indivíduos.

A população utilizada como a linhagem suscetível de referência (linhagem $\mathrm{S}$ ) foi coletada em 2000 num pomar abandonado na cidade de Piracicaba, São Paulo. A aplicação de pesticidas não era realizada neste pomar há mais de 5 anos.

\subsection{Criação de Brevipalpus phoenicis em laboratório}

A criação de B. phoenicis foi realizada sobre frutos de laranja das variedades Pera Rio ou Valência coletados em pomares sem aplicação de acaricidas. Os frutos 


\begin{tabular}{|c|c|c|c|c|c|c|c|c|c|}
\hline \multirow{2}{*}{ População } & \multicolumn{2}{|c|}{ Dados de coleta } & \multicolumn{7}{|c|}{ Histórico (Ano) } \\
\hline & Local & Mês / Ano & 1996 & 1997 & 1998 & 1999 & 2000 & 2001 & 2002 \\
\hline $\mathrm{S}$ & Piracicaba & 2000 & -1 & - & - & - & - & & \\
\hline BAR-1 & Barretos & $01 / 2001$ & - & $X^{2}$ & $\mathrm{X}$ & $\mathrm{X}$ & - & - & \\
\hline BAR- $2^{3}$ & & 09/2001 & & & - & $\mathrm{X}$ & $\mathrm{X}$ & - & \\
\hline BAR-3 & & $03 / 2002$ & - & $\mathrm{X}$ & $\mathrm{X}$ & $\mathrm{X}$ & - & - & $\mathrm{X}$ \\
\hline BAR-4 & & $04 / 2002$ & - & - & $\mathrm{X}$ & $\mathrm{X}$ & $\mathrm{X}$ & $\mathrm{X}$ & - \\
\hline BAR-5 & & $04 / 2002$ & - & - & $\mathrm{X}$ & $\mathrm{X}$ & $\mathrm{X}$ & $\mathrm{X}$ & $\mathrm{X}$ \\
\hline BAR-6 & & $04 / 2002$ & $\mathrm{X}$ & $\mathrm{X}$ & $\mathrm{X}$ & - & $\mathrm{X}$ & $\mathrm{X}$ & - \\
\hline BAR-7 & & $04 / 2002$ & - & - & $\mathrm{X}$ & - & $\mathrm{X}$ & $\mathrm{XX}$ & - \\
\hline GP-1 & Gavião Peixoto & 06/2001 & $\mathrm{X}$ & $\mathrm{M}^{4}$ & - & - & - & - & \\
\hline GP-2 & & 06/2001 & $\mathrm{X}$ & M & - & $\mathrm{X}$ & - & - & \\
\hline SCR- $1^{5}$ & Santa Cruz & $04 / 2002$ & & & & & $\mathrm{X}$ & - & - \\
\hline SCR-2 $2^{5}$ & do Rio Pardo & $04 / 2002$ & & & & & $\mathrm{X}$ & - & - \\
\hline SCR-3 $3^{5,6}$ & & $04 / 2002$ & & & & & - & - & - \\
\hline SCR-4 $4^{5,6}$ & & $04 / 2002$ & & & & & - & - & - \\
\hline
\end{tabular}

Ano sem aplicação do acaricida propargite

2 Ano com aplicação do acaricida propargite

${ }^{3}$ Histórico do uso de acaricida desde 1998

${ }^{4}$ Acaricida propargite em mistura

${ }^{5}$ Histórico do uso de acaricida desde 2000

${ }^{6}$ Pomar orgânico

Quadro 1 - Origem e histórico do uso de acaricidas nas populações de Brevipalpus phoenicis coletadas nos diferentes pomares comerciais de citros do Estado de São Paulo. 
coletados foram lavados em água corrente e após a secagem foram parafinados deixando uma arena de aproximadamente 8 a $16 \mathrm{~cm}^{2}$ circundada por cola adesiva (Tanglefoot ${ }^{\circledR}$ ) para confinar os ácaros. Uma mistura de areia, gesso, farinha de trigo e água na proporção de 4:1:1 foi pincelada nos frutos para simular os sintomas de verrugose que favorecem o desenvolvimento do ácaro-da-leprose (Martinelli et al., 1976; Nakano et al., 1987). Antes da utilização dos frutos, esses foram verificados para eliminação de qualquer estágio de desenvolvimento de ácaro-da-leprose proveniente do campo. Os frutos infestados com os ácaros foram colocados em caixas plásticas (dimensões de $41 \mathrm{x}$ 34 x $14 \mathrm{~cm}$ ) contendo uma prancha de isopor com 12 orifícios para acondicionamento dos frutos. A criação foi mantida em sala climatizada à $25 \pm 2{ }^{\circ} \mathrm{C}$, umidade relativa de $70 \pm 10 \%$ e fotofase de $14 \mathrm{~h}$. Os frutos foram renovados a cada 20 ou 30 dias, deixando a arena do fruto novo e do fruto infestado em contato por aproximadamente uma semana, para a transferência dos ácaros para o fruto novo.

\subsection{Procedimentos de bioensaio}

O método de bioensaio adotado foi o de contato residual. O acaricida utilizado foi o Omite ${ }^{\circledR} 720 \mathrm{CE}$ BR (720 g de propargite/L de produto comercial, concentrado emulsionável, Uniroyal Química S.A.). As concentrações definidas para os bioensaios foram preparadas a partir da diluição do produto comercial em água destilada.

Os bioensaios foram realizados em discos de folhas de $2,6 \mathrm{~cm}$ de diâmetro coletados em um pomar de laranja da variedade Valência sem aplicação de acaricidas. Os discos de folha foram mantidos sobre papel toalha umedecido com água até a pulverização do produto sobre a superfície adaxial da folha. A pulverização foi realizada com o uso da torre de pulverização de Potter (Burkard Manufacturing, Rickmansworth, Inglaterra) calibrada à pressão de 68,95 kPa $\left(10 \mathrm{lb} / \mathrm{pol}^{2}\right)$. Os discos de folha foram pulverizados individualmente com um volume de $2 \mathrm{ml}$ de solução, obtendo um depósito médio de $1,5 \mathrm{mg}$ de solução/ $\mathrm{cm}^{2}$. Após a aplicação, os discos foram retornados sobre o papel umedecido até a secagem do produto, por cerca de 30 minutos, sendo em seguida acondicionados individualmente em placas acrílicas de $3,5 \mathrm{~cm}$ de 
diâmetro (Falcon 1008, Becton Dickinson Labware, Lincoln Park, NJ, Estados Unidos) contendo aproximadamente $2 \mathrm{ml}$ de uma mistura não-geleificada de ágar-água na concentração de $2,5 \%$. Uma barreira dessa mistura foi construída ao redor dos discos de folha para evitar a fuga dos ácaros (adaptado de Kabir et al., 1993).

Foram transferidos dez ácaros adultos para cada placa com auxílio de um pincel com um pêlo e dois microscópios estereoscópicos. Após a infestação com os ácaros, as placas foram tampadas e mantidas em câmara climatizada regulada à $25 \pm 1{ }^{\circ} \mathrm{C}$ e fotofase de $14 \mathrm{~h}$. Foram realizados bioensaios para avaliação da mortalidade com $24 \mathrm{e}$ $48 \mathrm{~h}$ de exposição para a linhagem S. A escolha do melhor tempo de exposição para condução dos bioensaios foi baseado no coeficiente angular da curva concentraçãomortalidade e no intervalo de confiança da $\mathrm{CL}_{50}$, ou seja, a concentração letal que causa $50 \%$ de mortalidade da população. O critério de mortalidade adotado para avaliação consistiu em reunir os ácaros no centro do disco de folha e os indivíduos que não responderam com movimentos vigorosos e coordenados de seus apêndices foram colocados com a face ventral voltada para cima e os que não conseguiram voltar a posição normal foram considerados mortos. Os bioensaios que apresentaram mortalidade superior a $15 \%$ na testemunha foram descartados, assim como os bioensaios com presença de ácaros superior a $15 \%$ na barreira de ágar-água.

\subsection{Caracterização da linha-básica de suscetibilidade de Brevipalpus phoenicis ao propargite}

Para caracterização da suscetibilidade de B. phoenicis ao propargite foi utilizada a linhagem S. Foram utilizadas concentrações distribuídas em escala logarítmica entre 100 e $720 \mu \mathrm{g}$ de propargite/ml de água destilada [I.A. (ppm)]. Cada repetição foi constituída por duas placas como testemunha (pulverizadas com água destilada) e quatro placas por concentração, sendo repetidos cinco vezes ao longo do tempo. Os dados de mortalidade foram submetidos à análise de Probit utilizand o o programa POLO-PC (LeOra Software, 1987) para estimar a CL50. A partir da curva de concentração-mortalidade da linhagem $\mathrm{S}$ ao propargite foram definidas duas 
concentrações que ocasionaram mortalidade entre 80 e 95\% como concentrações diagnósticas para o monitoramento da resistência de B. phoenicis ao propargite. O nível de significância do teste foi de $\alpha=0,05$.

\subsection{Monitoramento da suscetibilidade das populações de Brevipalpus phoenicis ao propargite}

As populações utilizadas para o monitoramento da suscetibilidade de $B$. phoenicis ao propargite foram mencionadas na coleta das populações de B. phoenicis, referente ao item 3.1. As concentrações diagnósticas utilizadas para o monitoramento foram definidas na caracterização da suscetibilidade de B. phoenicis, referente ao item 3.4. Cada repetição foi constituída por duas placas como testemunha (pulverizadas com água destilada) e quatro placas por concentração, sendo repetidos cinco vezes ao longo do tempo.

O delineamento experimental adotado foi inteiramente casualizado e os dados de proporção de sobrevivência $(X)$ foram transformados para $\operatorname{arc} \operatorname{sen}(\sqrt{X})$, sendo $X$ a razão entre o número de ácaros vivos e número total de ácaros testados, e submetidos à análise de variância pelo teste $\mathrm{F}$ e as médias comparadas pelo teste bilateral de Dunnett, tendo a linhagem $\mathrm{S}$ como referência. O nível de significância do teste foi de $\alpha=0,05$.

\subsection{Caracterização da resistência de Brevipalpus phoenicis ao propargite}

Para caracterização da resistência de $B$. phoenicis ao propargite foi escolhida uma população de pomar comercial que sofreu intenso uso de propargite nos últimos anos e apresentou baixa mortalidade no monitoramento da suscetibilidade das populações de B. phoenicis, referente ao item 3.5. Foi realizada a caracterização toxicológica dessa população utilizando concentrações distribuídas em escala logarítmica entre 180 e $5.600 \mu \mathrm{g}$ de propargite/ml de água destilada [I.A. (ppm)]. 
Para obter a linhagem resistente $(\mathrm{R})$ foi realizado um ciclo de pressão de seleção em laboratório, utilizando o método de bioensaio descrito no item 3.3. A seleção foi realizada com a concentração diagnóstica que proporcionou mortalidade de aproximadamente $80 \%$ na linhagem $\mathrm{S}$. Os sobreviventes a esta concentração foram transferidos para frutos de laranja, conforme descrito no item 3.2, para multiplicação. Para caracterização toxicológica da linhagem $\mathrm{R}$ foram utilizadas concentrações distribuídas em escala logarítmica entre 720 e $5.600 \mu \mathrm{g}$ de propargite/ml de água destilada [I.A. (ppm)].

Os bioensaios de caracterização toxicológica foram repetidos cinco vezes ao longo do tempo. Cada repetição foi constituída por duas placas como testemunha (pulverizadas com água destilada) e quatro placas por concentração. Os dados de mortalidade foram submetidos à análise de Probit para estimar as $\mathrm{CL}_{50}$. As linhagens $\mathrm{S}$ e $\mathrm{R}$ foram confrontadas pelo teste de paralelismo e de igualdade, utilizando o programa POLO-PC, com a finalidade de comparar os coeficientes angulares e lineares. Foi observado a ocorrência ou não da sobreposição dos intervalos de confiança das CL50 de cada linhagem. A razão de resistência foi obtida pela divisão da $\mathrm{CL}_{50}$ da linhagem $\mathrm{R}$ pela $\mathrm{CL}_{50}$ da linhagem S. O nível de significância do teste foi de $\alpha=0,05$.

\subsection{Interação de Brevipalpus phoenicis, propargite e citros}

\subsubsection{Efeito do modo de exposição de Brevipalpus phoenicis ao propargite}

O efeito do modo de exposição de $B$. phoenicis ao propargite na discriminação das linhagens S e R foi avaliado por meio de dois métodos de bioensaio: contato residual e contato direto. O procedimento do bioensaio de contato residual foi descrito no item 3.3 .

Para realização do bioensaio de contato direto foram utilizados discos de folha de laranja de 2,6 cm de diâmetro acondicionadas em placas acrílicas de 3,5 cm de diâmetro contendo aproximadamente $2 \mathrm{ml}$ de uma mistura não-geleificada de ágar-água a 2,5\%. Uma barreira dessa mistura foi construída ao redor dos discos de folha para 
evitar a fuga dos ácaros. Foram transferidos dez ácaros adultos para cada disco de folha. Após a transferência dos ácaros, as placas foram mantidas em câmara climatizada regulada à $25 \pm 1{ }^{\circ} \mathrm{C}$ por cerca de uma hora. Posteriormente, a mistura geleificada de ágar-água com os discos de folha (arena) foram retiradas das placas com auxílio de uma espátula, sendo transferidos para uma bandeja. Em seguida, as arenas foram colocadas sobre uma placa de vidro de $5 \times 5 \mathrm{~cm}$ e pulverizadas individualmente utilizando a torre de Potter calibrada à pressão de $68,95 \mathrm{kPa}$ com um volume de $2 \mathrm{ml}$ de solução. Após a secagem do produto, as arenas foram acondicionadas em placas acrílicas de $5,5 \mathrm{~cm}$ de diâmetro (Corning 25060-60, Corning Glass Works, NY, Estados Unidos) que continham aproximadamente $3 \mathrm{ml}$ da mistura de ágar-água. $\mathrm{O}$ critério de mortalidade adotado foi conforme descrito no item 3.3. Os bioensaios que apresentaram mortalidade superior a $15 \%$ na testemunha foram descartadas, assim como aqueles com a presença de ácaros na barreira de ágar-água superior a 15\% (adaptado de Kabir et al., 1993).

Foram utilizadas concentrações distribuídas em escala logarítmica entre 100 e $560 \mu \mathrm{g}$ de propargite/ml de água destilada [I.A. (ppm)] (linhagem S) e 720 e $5.600 \mu \mathrm{g}$ de propargite/ml de água destilada [I.A. (ppm)] (linhagem R) para o método de contato direto. As concentrações utilizadas no método de contato residual foram descritas no item 3.4 e 3.6 para as linhagens $\mathrm{S}$ e $\mathrm{R}$ respectivamente.

Cada repetição foi constituída por duas placas como testemunha (pulverizadas com água destilada) e quatro placas por concentração, sendo repetidos cinco vezes ao longo do tempo. Os dados de mortalidade das linhagens $\mathrm{S}$ e $\mathrm{R}$ foram submetidos à análise de Probit para estimar as $\mathrm{CL}_{50}$. As curvas de concentração-resposta das linhagens $\mathrm{S}$ e $\mathrm{R}$ de cada método de exposição foram confrontadas pelo teste de paralelismo e de igualdade. Foi observado a ocorrência ou não da sobreposição dos intervalos de confiança das $\mathrm{CL}_{50}$ de cada linhagem. A razão de resistência foi obtida pela divisão da $\mathrm{CL}_{50}$ da linhagem $\mathrm{R}$ pela $\mathrm{CL}_{50}$ da linhagem $\mathrm{S}$. $\mathrm{O}$ nível de significância do teste foi de $\alpha=0,05$. 


\subsubsection{Persistência da atividade biológica de propargite sobre Brevipalpus phoenicis}

O experimento foi realizado no sítio São João da Glória, Mogi Mirim, São Paulo, num pomar de laranja da variedade Valência de oito anos de idade num espaçamento de 7 × 4 m. A concentração do acaricida propargite (Omite ${ }^{\circledR} 720 \mathrm{CE} \mathrm{BR}$ ) utilizada foi de $720 \mathrm{~g}$ de propargite/1000 L de água (concentração recomendada para citros). A pulverização foi realizada no dia 03 de setembro de 2002 utilizando um pulverizador tratorizado da marca Citromaq de capacidade de $2.000 \mathrm{~L}$.

Para avaliar a persistência da atividade biológica de propargite sobre as linhagens $\mathrm{S}$ e $\mathrm{R}$ de B. phoenicis foram realizadas coletas de frutos antes da aplicação (testemunha) e uma hora após a aplicação (0 dia), 1, 3, 5, 7, 10 e 14 dias após a aplicação. Foram coletados seis frutos da parte externa e do terço médio da planta para cada linhagem, sendo coletados dois frutos de cada planta e delimitada a superfície que estava mais exposta à pulverização. Na área delimitada foi construída uma arena de aproximadamente $2,5 \mathrm{~cm}$ de diâmetro circundada por uma fita plástica de $2 \mathrm{~cm}$ de largura, funcionando como suporte para a camada de algodão hidrófilo umedecida com água destilada e uma camada não geleificada de ágar-água a 2,5\% para impedir a fuga dos ácaros.

Antes da transferência dos ácaros para as arenas, essas foram verificadas para eliminação de qualquer estágio de desenvolvimento do ácaro-da-leprose. Em seguida, foram transferidos vinte ácaros adultos de uma determinada linhagem em cada fruto com o auxílio de um pincel com um pêlo e dois microscópios estereoscópicos. Os frutos foram colocados em caixas plásticas (dimensões de 41 x 34 x $14 \mathrm{~cm}$ ) acondicionados em prancha de isopor e mantidos em sala climatizada à $25 \pm 2{ }^{\circ} \mathrm{C}$, umidade relativa de $70 \pm$ $10 \%$ e fotofase de $14 \mathrm{~h}$. A mortalidade foi avaliada 24 e $48 \mathrm{~h}$ após a infestação. O critério de mortalidade adotado foi conforme descrito no item 3.3. As repetições que apresentaram presença de ácaros na barreira de ágar-água superior a 15\% foram descartadas. Os dados de proporção de mortalidade $(X)$, sendo $X$ a razão entre o número de ácaros mortos e número total de ácaros testados, foram submetidos à análise 
sequiencial de deviance pelo teste $\mathrm{F}$, ao nível de significância de $5 \%$, e proposto um modelo de regressão binomial. 


\section{RESULTADOS E DISCUSSÃO}

\subsection{Caracterização da linha-básica de suscetibilidade de Brevipalpus phoenicis ao propargite}

As curvas de caracterização toxicológica da linhagem suscetível de Brevipalpus phoenicis (Geijskes) ao propargite utilizando bioensaio de contato residual avaliadas com 24 e 48 h após a infestação estão representadas na Tabela 1.

Não foi verificada sobreposição dos intervalos de confiança das CL50 nas avaliações com 24 e 48 h, indicando que as curvas de concentração-mortalidade foram diferentes, ou seja, houve aumento na resposta com aumento do período de exposição, confirmado pelo teste de igualdade e paralelismo que rejeitou a hipótese de igualdade das curvas $\left(\chi^{2}=160,77 ;\right.$ g.l. $\left.=2 ; \mathrm{P}<0,05\right)$, mas aceitou a hipótese de igualdade dos coeficientes angulares $\left(\chi^{2}=0,53 ;\right.$ g.l. $\left.=1 ; \mathrm{P}>0,05\right)$ demonstrando que as curvas foram paralelas (Figura 1). Segundo ffrench-Constant \& Roush (1990), o coeficiente angular permite a escolha do método de bioensaio mais adequado, isto é, quanto maior o coeficiente angular mais adequado é o bioensaio para os estudos toxicológicos. Nesse caso pode-se considerar ambos os períodos de exposição adequados para realização desses estudos em B. phoenicis, porém, a curva de concentração-mortalidade avaliada após $24 \mathrm{~h}$ de exposição foi selecionada para avaliação da suscetibilidade de B. phoenicis ao propargite em estudos futuros, devido à obtenção dos resultados de maneira mais rápida.

A caracterização toxicológica da suscetibilidade é a primeira etapa para implementação de programas de manejo da resistência, por isso é importante a escolha 
Tabela 1. Resultados da análise de Probit para a caracterização toxicológica da linhagem suscetível (S) de Brevipalpus phoenicis ao propargite com avaliação realizada 24 e 48 horas após a exposição.

\begin{tabular}{|c|c|c|c|c|c|}
\hline $\begin{array}{c}\text { Período de } \\
\text { exposição (h) }\end{array}$ & $\mathrm{n}^{\mathrm{a}}$ & $\begin{array}{c}\text { Coeficiente } \\
\text { Angular ( } \pm \text { EP) }\end{array}$ & $\begin{array}{c}\mathrm{CL}_{50}(\mu \mathrm{g} \text { i.a./ml) } \\
(\mathrm{IC} 95 \%)\end{array}$ & $\chi^{2}$ & g.l. ${ }^{b}$ \\
\hline 24 & 1.087 & $4,64 \pm 0,28$ & $\begin{array}{c}217,51 \\
(207,07-228,35)\end{array}$ & 2,25 & 3 \\
\hline 48 & 883 & $4,73 \pm 0,27$ & $\begin{array}{c}129,19 \\
(122,09-136,68)\end{array}$ & 0,14 & 2 \\
\hline
\end{tabular}

${ }^{a}$ Número de ácaros testados

${ }^{\mathrm{b}}$ Graus de liberdade

de um método adequado. Atualmente, a tendência é para o uso de métodos mais eficientes, rápidos, que aumentem a discriminação entre os genótipos e simulem a maneira de exposição dos organismos em campo (Dennehy et al., 1983; ffrenchConstant \& Roush, 1990; Roush \& Miller, 1986). Por meio desse bioensaio pode-se, por exemplo, detectar a evolução da resistência, monitorar a suscetibilidade de populações, fazer recomendações e avaliar as estratégias de manejo da resistência (ffrench-Constant \& Roush, 1990).

As concentrações diagnósticas definidas pela caracterização toxicológica da linhagem suscetível (S) para o monitoramento da suscetibilidade foram 320 e $720 \mu \mathrm{g}$ de propargite/ml de água [I.A. (ppm)], essas concentrações foram escolhidas porque causaram mortalidade ( \pm erro padrão da média) de 80,35 $(44,31)$ e 98,46\% $( \pm 1,54)$ respectivamente. Os estudos de evolução da resistência tem sido realizados por curvas de concentração-resposta, onde é estimada a $\mathrm{CL}_{50}$ e por concentrações diagnósticas ou discriminatórias. Em trabalhos de monitoramento da suscetibilidade, o uso das concentrações diagnósticas ou discriminatórias são recomendadas por serem mais eficientes do que a estimativa da $\mathrm{CL}_{50}$, principalmente quando a freqüência de resistência ainda é baixa, porque todos os indivíduos amostrados são testados numa 


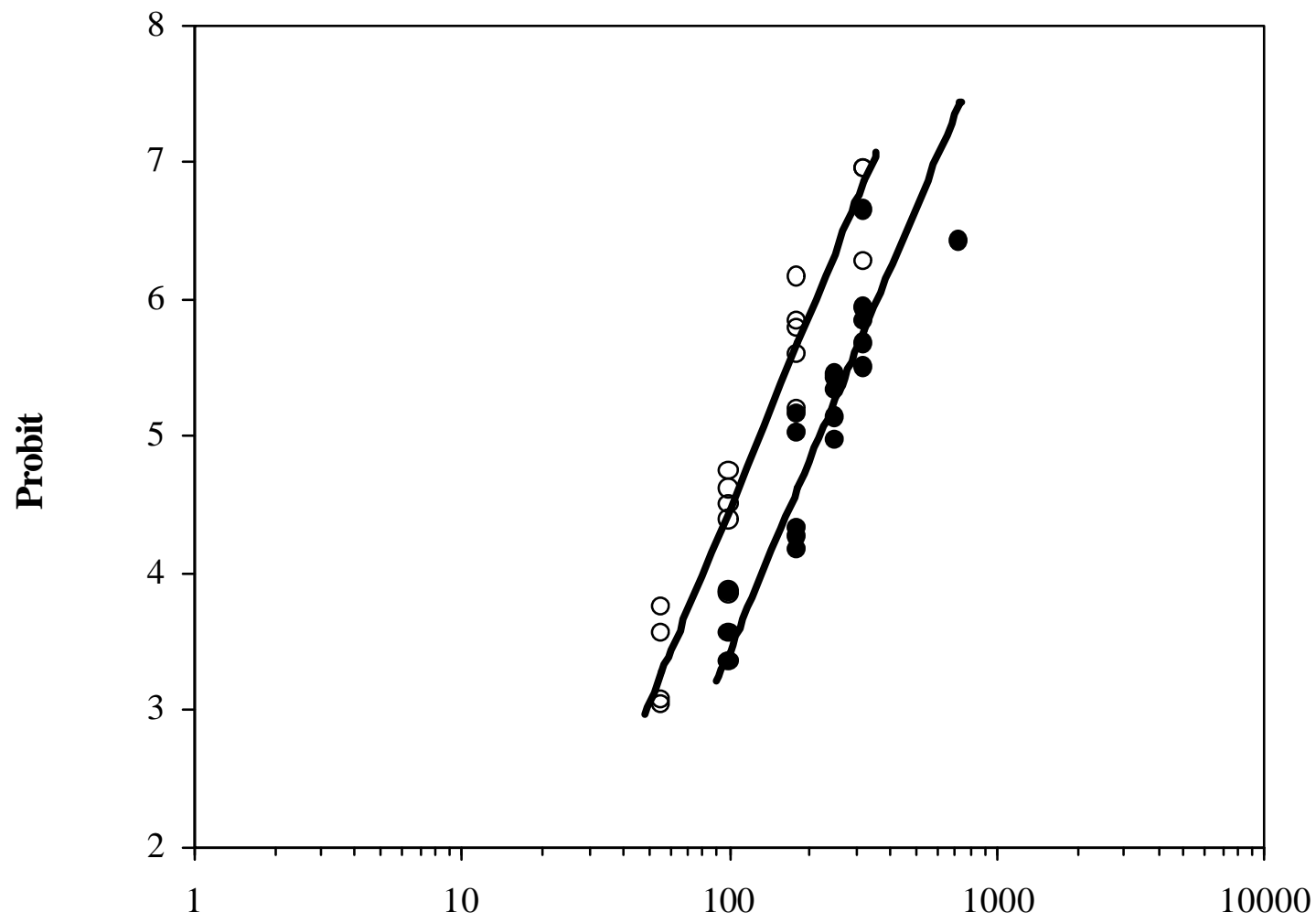

$\mu g$ de propargite/ml de água

Figura 1 - Caracterização toxicológica da linhagem suscetível (S) de Brevipalpus phoenicis ao propargite para os períodos de exposição de $24(\bullet)$ e 48 horas (O). 
concentração adequada (ffrench-Constant \& Roush, 1990; Roush \& Miller, 1986). Segundo Halliday \& Burnham (1990) para o monitoramento da suscetibilidade de populações até três concentrações diagnósticas, entre a CL50 e CL95 da linhagem suscetível de referência, devem ser definidas, principalmente quando são detectados casos de baixa razão de resistência, ou seja, ocorre a sobreposição das curvas de concentração-resposta da linhagem suscetível com a de campo.

\subsection{Monitoramento da suscetibilidade de populações de Brevipalpus phoenicis ao propargite}

Os resultados do monitoramento da suscetibilidade de $B$. phoenicis ao propargite estão representados na Tabela 2 e Figura 2. As concentrações diagnósticas de 320 e $720 \mu \mathrm{g}$ de propargite/ml de água [I.A. (ppm)] revelaram diferenças significativas entre as populações coletadas nos diferentes pomares de citros do Estado de São Paulo $(\mathrm{F}=15,66 ;$ g.l.= 13, 56; $\mathrm{P}<0,05)$ e $(\mathrm{F}=31,02 ;$ g.l.= 13, 56; $\mathrm{P}<0,05)$ respectivamente.

Embora somente em algumas populações de Barretos foram observadas baixa suscetibilidade ao propargite não se pode afirmar que a resistência ocorra apenas nessa localidade porque foram utilizadas poucas populações provenientes das localidades de Gavião Peixoto e Santa Cruz do Rio Pardo e com poucos registros de uso do propargite.

A população BAR-1 apresentou sobrevivência ( \pm erro padrão da média) de $63,80 \%( \pm 8,46)$ na concentração de $720 \mu \mathrm{g}$ de propargite/ml de água [I.A. (ppm)] com três aplicações de propargite num período de seis anos, enquanto as populações BAR-4 e BAR-5 não apresentaram suscetibilidade significativamente diferente da linhagem $\mathrm{S}$ e apresentaram sobrevivência $( \pm$ erro padrão da média) de $11,59 \notin 3,79)$ e 15,50\% $( \pm$ 3,00) com quatro e cinco aplicações desse acaricida, respectivamente, durante o mesmo período.

O restabelecimento da suscetibilidade em populações de artrópodes geralmente está relacionado ao custo adaptativo dos indivíduos resistentes na ausência de pressão de seleção e à imigração de indivíduos suscetíveis (Georghiou \& Taylor, 1977b). Portanto a estabilidade da resistência pode dificultar a implementação de estratégias de manejo da 
Tabela 2. Porcentagem média $( \pm$ erro padrão da média) de sobrevivência das populações de Brevipalpus phoenicis coletadas em diferentes talhões de pomares comerciais de citros do Estado de São Paulo nas concentrações diagnósticas de 320 e $720 \mu \mathrm{g}$ de propargite/ml de água.

\begin{tabular}{|c|c|c|c|c|}
\hline População & $\mathrm{n}^{\mathrm{a}}$ & $\begin{array}{c}320 \text { ( } \mu \mathrm{g} \text { propargite/ml) } \\
\text { \%Sobrevivência } \pm \text { EPM }\end{array}$ & $\mathrm{n}$ & $\begin{array}{l}720(\mu \mathrm{g} \text { propargite } / \mathrm{ml})^{\mathrm{b}} \\
\% \text { Sobrevivência } \pm \mathrm{EPM}\end{array}$ \\
\hline $\mathrm{S}$ & 198 & $21,66 \pm 5,17 a$ & 191 & $3,79 \pm 1,39 \mathrm{~A}$ \\
\hline SCR-1 & 201 & $9,70 \pm 4,47 \mathrm{a}$ & 199 & $0,00 \pm 0,00 \mathrm{~A}$ \\
\hline SCR-3 & 200 & $12,50 \pm 5,70 \mathrm{a}$ & 199 & $1,03 \pm 1,03 \mathrm{~A}$ \\
\hline BAR-7 & 197 & $16,19 \pm 3,77 \mathrm{a}$ & 199 & $0,95 \pm 0,95 \mathrm{~A}$ \\
\hline SCR-4 & 200 & $17,68 \pm 7,91 \mathrm{a}$ & 197 & $1,56 \pm 1,05 \mathrm{~A}$ \\
\hline SCR-2 & 203 & $21,87 \pm 7,22 \mathrm{a}$ & 199 & $2,00 \pm 2,00 \mathrm{~A}$ \\
\hline BAR-4 & 200 & $34,00 \pm 8,35 \mathrm{a}$ & 199 & $11,59 \pm 3,79 \mathrm{~A}$ \\
\hline BAR-5 & 200 & $38,54 \pm 5,34 \mathrm{a}$ & 200 & $15,50 \pm 3,00 \mathrm{~A}$ \\
\hline GP-2 & 204 & $41,34 \pm 10,15 a$ & 202 & $15,51 \pm 3,57 \mathrm{~A}$ \\
\hline GP-1 & 197 & $44,49 \pm 4,71 \mathrm{a}$ & 199 & $5,01 \pm 1,77 \mathrm{~A}$ \\
\hline BAR-2 & 201 & $55,26 \pm 2,31 b$ & 200 & $36,07 \pm 3,98 \mathrm{~B}$ \\
\hline BAR-6 & 199 & $58,37 \pm 3,94 b$ & 200 & $45,89 \pm 4,84 \mathrm{~B}$ \\
\hline BAR-3 & 198 & $68,51 \pm 4,54 b$ & 197 & $46,62 \pm 7,63 \mathrm{~B}$ \\
\hline BAR-1 & 200 & $88,33 \pm 4,01 b$ & 201 & $63,80 \pm 8,46 \mathrm{~B}$ \\
\hline
\end{tabular}

\footnotetext{
${ }^{a}$ Número de ácaros testados

${ }^{\text {b }}$ Para realização da análise da variância as médias referentes a concentração diagnóstica de 720 $\mu \mathrm{g}$ de propargite/ $\mathrm{ml}$ de água foram transformadas em $\operatorname{arcsen}(\sqrt{\mathrm{X}})$

Médias originais seguidas pela mesma letra na coluna, minúsculas e maiúsculas para 320 e 720 $\mu \mathrm{g}$ propargite/ml de água, respectivamente, não diferem da testemunha (linhagem $\mathrm{S}$ ) pelo teste bilateral de Dunnett, ao nível de significância de 5\%
}

resistência (Roush \& McKenzie, 1987). Em condições de laboratório, a estabilidade da resistência ao propargite foi verificada para Tetranychus pacificus McGregor coletada em amêndoa na Califórnia, Estados Unidos (Hoy \& Conley, 1989). Em B. phoenicis foi 


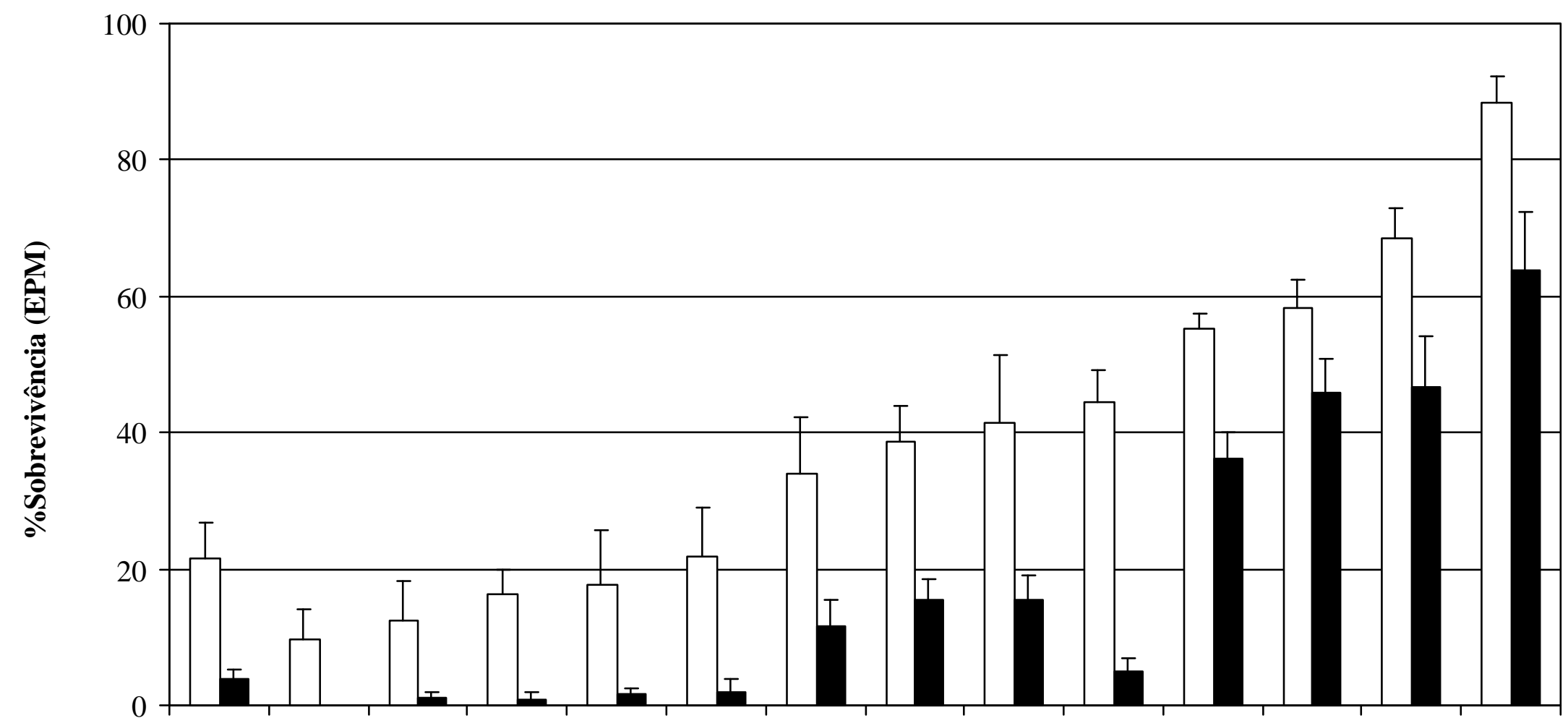

S SCR-1 SCR-3 BAR-7 SCR-4 SCR-2 BAR-4 BAR-5 GP-2 GP-1 BAR-2 BAR-6 BAR-3 BAR-1

\section{Populações}

Figura 2 - Porcentagem de sobrevivência (erro padrão da média) de populações de Brevipalpus phoenicis ao propargite coletadas em diferentes pomares de citros do Estado de São Paulo nas concentrações diagnósticas de 320 ( $\square$ ) e 720 ( ) $\mu \mathrm{g}$ de propargite/ml de água. 
verificado que em condições laboratoriais, a resistência ao hexitiazox foi estável (Campos \& Omoto, 2002) e ao dicofol foi instável. A instabilidade da resistência de $B$. phoenicis ao dicofol foi relacionada ao custo adaptativo dos resistentes, principalmente devido à menor fecundidade e longevidade (Alves, 1999). Então para contribuir na elaboração de estratégias de manejo, o conhecimento da estabilidade da resistência ao propargite é de grande importância para implementação de um programa de manejo da resistência de B. phoenicis. Entretanto, o contínuo processo de seleção pode aumentar o valor adaptativo dos resistentes na ausência de pressão de seleção, devido a coadaptação (Georghiou, 1983; McKenzie et al., 1982; Roush \& McKenzie, 1987).

As populações BAR-4, BAR-5 e BAR-7 de B. phoenicis foram provenientes de pomares próximos a plantas de sansão-do-campo, Mimosa caesalpiniaefolia Benth., utilizadas como cerca-viva. A presença de grande número de plantas hospedeiras do ácaro-da-leprose, sejam plantas cultivadas, daninhas ou utilizadas como cercas-vivas nos pomares de citros poderiam constituir um reservatório natural do ácaro-da-leprose, podendo ser de grande importância como fonte de ácaros suscetíveis que pela imigração poderiam contribuir para o restabelecimento da suscetibilidade. Segundo Alves et al. (2002), a dispersão aérea do ácaro-da-leprose nos pomares de citros ocorre, embora em pequena quantidade, principalmente próximo à periferia desses pomares. Entretanto, sob o ponto de vista de controle, esse fato pode ser prejudicial por ser um provável foco de infestação. Dessa forma, a escolha de plantas para cercas-vivas ou quebra-ventos deve levar em consideração a capacidade de colonização pelo ácaro e se essas plantas são hospedeiras do vírus da leprose dos citros. As plantas hibisco, malvavisco, grevílea e sansão-do-campo utilizadas como cercas-vivas são hospedeiras do ácaro-da-leprose, mas os ácaros mantidos, em condições laboratoriais, nessas plantas não foram capazes de transmitir os sintomas da doença para as variedades de citros Natal e Valência (Maia et al., 2002a; Maia et al., 2002b). Entretanto, estudos mais aprofundados devem ser realizados para verificar a razão da falta de manifestação dos sintomas do vírus da leprose a partir dos ácaros provenientes dessas plantas, uma vez que os sintomas podem não se manifestar, mesmo na presença do vírus (Rodrigues et al. 2001). Dessa forma, para recomendar a manutenção de cercas-vivas nos pomares de citros como estratégia de 
manejo da resistência é fundamental conhecer a dispersão de B. phoenicis e as diferenças de suscetibilidade entre populações provenientes de diferentes hospedeiros. A presença de refúgios, ou seja, áreas não-tratadas, também podem ocorrer na própria planta de citros, principalmente nas áreas mais internas, portanto a qualidade da aplicação é de grande importância para o controle do ácaro-da-leprose.

O primeiro caso de resistência de ácaros ao propargite foi documentada para Tetranychus urticae Koch em pomares de maçã que não tinham recebido aplicação do propargite, então foi sugerido resistência cruzada com o acaricida tetradifom porque ambos apresentam enxofre na molécula (Unwin, 1973) e atuam na respiração celular (Corbett et al., 1984; Kadir \& Knowles, 1991). A resistência cruzada entre dicofol e propargite em B. phoenicis (Alves et al., 2000a) e T. urticae (Fergusson-Kolmes et al., 1991) não foram constatadas, mas foram detectadas em Tetranychus cinnabarinus (Boisduval) (Mansour \& Plaut, 1979) e T. urticae (Dennehy et al., 1987). Segundo Grafton-Cardwell et al. (1987) para T. urticae e T. pacificus pode ser um caso de resistência múltipla porque apenas 9 e $16 \%$ das populações estudadas, respectivamente, apresentaram resistência a ambos acaricidas. Devido ao fato de B. phoenicis ser haplóide com dois cromossomos não homólogos (Helle et al., 1980; Pijnacker et al., 1980; Weeks et al., 2001) que pode favorecer o desenvolvimento de resistência múltipla (Omoto, 1998) e associado a diferenças no histórico de aplicação de acaricidas pode ocasionar diferenças na evolução da resistência.

Outro fator importante para o desenvolvimento da resistência em B. phoenicis é o modo de reprodução por partenogênese que pode acelerar a evolução da resistência porque os descendentes de uma progenitora resistente serão resistentes, mas pode limitar a variabilidade genética de uma população. Pelos resultados obtidos pode-se inferir que as populações apresentam grande variabilidade na suscetibilidade ao propargite, fato também verificado por Omoto et al. (2000) para o dicofol e por Campos \& Omoto (2002) para o hexitiazox. Weeks et al. (2000) verificaram diferenças genéticas em populações de B. phoenicis utilizando marcadores moleculares. Nesse caso, assumindo que a migração tenha baixo impacto no aumento da variabilidade nas populações de $B$. 
phoenicis, então o desenvolvimento da resistência poderia ocorrer rapidamente em algumas populações em função da sua composição genética.

Em termos práticos, nas populações que apresentaram baixa mortalidade nos bioensaios de concentrações diagnósticas o uso de propargite deve ser evitado. Portanto, para recomendações de estratégias de manejo visando retardar a evolução da resistência, além dos estudos comentados anteriormente, deve-se elaborar um método de bioensaio realizado em condições de campo para validar os resultados apresentados pelo monitoramento em condições de laboratório. Sendo esta uma importante etapa em trabalhos futuros para a implementação de um programa de manejo da resistência de $B$. phoenicis ao propargite.

\subsection{Caracterização da resistência de Brevipalpus phoenicis ao propargite}

O resultado da caracterização da resistência de B. phoenicis ao propargite está representado na Tabela 3. A CL50 (IC 95\%) estimada para a linhagem S foi 217,51 $(207,07-228,35) \mu \mathrm{g}$ de propargite/ml de água [I.A. (ppm)] e coeficiente angular $\notin$ erro

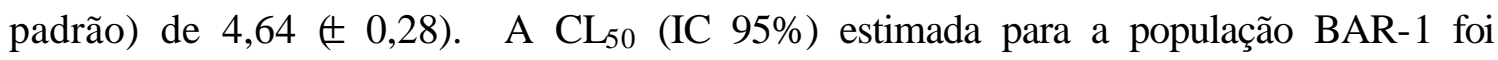
890,77 (509,58-1.474,86) $\mu \mathrm{g}$ de propargite/ml de água [I.A. (ppm)] e coeficiente angular ( \pm erro padrão) de 2,14 $( \pm 0,99)$. Não foi observada sobreposição dos intervalos de confiança, indicando que as populações foram diferentes, resultado confirmado pelo teste de igualdade e paralelismo que rejeitou ambas hipóteses $\left(\chi^{2}=500,51\right.$; g.1.= 2; $\mathrm{P}<0,05)$ e $\left(\chi^{2}=91,60 ;\right.$ g.l. $\left.=1 ; \mathrm{P}<0,05\right)$ respectivamente.

O coeficiente angular pode demonstrar a homogeneidade de uma população, isto é, quanto maior esse valor mais homogênea é a população (Hoskins \& Gordon, 1956). Portanto, os valores dos coeficientes angulares mostraram que a população BAR-1 foi mais heterogênea do que a linhagem $S$, indicando maior variabilidade genética que possibilita a seleção dos indivíduos resistentes, tanto em laboratório como em campo, mas também pode favorecer o retorno à suscetibilidade, na ausência de pressão de seleção, isto é, em populações que apresentam alta freqüência de indivíduos 
suscetíveis associado ao custo adaptativo dos indivíduos resistentes pode-se esperar rápido retorno à suscetibilidade. Entretanto, essa diferença nos resultados pode estar relacionada à seleção de indivíduos mais adaptados às condições de laboratório devido à maior permanência da linhagem S nessas condições do que a população BAR-1.

Tabela 3. Resultados da análise de Probit para as caracterizações toxicológicas da linhagem suscetível (S), da população BAR-1 e da linhagem resistente (R) de Brevipalpus phoenicis ao propargite.

\begin{tabular}{ccccccr}
\hline Linhagem & $\mathrm{n}^{\mathrm{a}}$ & $\begin{array}{c}\text { Coeficiente } \\
\text { Angular }( \pm \mathrm{EP})\end{array}$ & $\begin{array}{c}\mathrm{CL}_{50}(\mu \mathrm{g} \text { i.a./ml }) \\
(\mathrm{IC} \mathrm{95 \% )}\end{array}$ & $\chi^{2}$ & g.l. $^{\mathrm{b}}$ & $\mathrm{RR}^{\mathrm{c}}$ \\
\hline $\mathrm{S}$ & 1.087 & $4,64 \pm 0,28$ & $\begin{array}{c}217,51 \\
(207,07-228,35)\end{array}$ & 2,25 & 3 & - \\
& & & & & \\
BAR-1 & 1.274 & $2,14 \pm 0,99$ & 890,77 & 48,51 & 4 & 4,09 \\
& & & $(509,58-1.474,86)$ & & & \\
$\mathrm{R}$ & 1.089 & $3,40 \pm 0,18$ & $2.195,43$ & 12,71 & 3 & 10,09
\end{tabular}

${ }^{a}$ Número de ácaros testados

${ }^{\mathrm{b}}$ Graus de liberdade

${ }^{c}$ Razão de Resistência

Para obter a linhagem $\mathrm{R}$ foram submetidos 1.649 ácaros da população BAR-1 à pressão de seleção utilizando a concentração diagnóstica de $320 \mu \mathrm{g}$ de propargite/ml de água [I.A. (ppm)]. A mortalidade $(+$ erro padrão da média) observada no processo de seleção foi de $16,48 \%(+3,99)$, embora esses valores tenham sido baixos foi verificado um a três dias após avaliação dos bioensaios uma grande mortalidade dos sobreviventes. Para os experimentos de seleção em laboratório é recomendado a utilização de baixas concentrações que permitam a sobrevivência entre 10 e $50 \%$ da população e um grande 
número de indivíduos para reduzir a possibilidade de perda de importantes genes que conferem a resistência (Groeters \& Tabashnik, 2000).

A CL50 estimada para a linhagem R (IC 95\%) foi de 2.195,43 (1.759,23$2.808,21) \mu \mathrm{g}$ de propargite/ml de água [I.A. (ppm)] e coeficiente angular ( \pm erro padrão) de $3,40 \notin 0,18)$. Não foi observada sobreposição dos intervalos de confiança com a linhagem $\mathrm{S}$, indicando que as respostas foram diferentes, resultado confirmado pelo teste de igualdade e paralelismo que rejeitou ambas hipóteses $\chi^{2}=914,43 ;$ g.l. $\left.=2 ; \mathrm{P}<0,05\right)$ e $\left(\chi^{2}=15,17 ;\right.$ g.l.= $\left.1 ; \mathrm{P}<0,05\right)$, respectivamente, mesma resposta foi observada com a população BAR-1 $\left(\chi^{2}=257,43 ;\right.$ g.l.= $\left.2 ; \mathrm{P}<0,05\right)$ e $\left(\chi^{2}=41,07 ;\right.$ g.l.= $\left.1 ; \mathrm{P}<0,05\right)$ respectivamente (Figura 3). A razão de resistência estimada para a linhagem $\mathrm{R}$ foi de 10,09 vezes $\left(\mathrm{CL}_{50} \mathrm{R} / \mathrm{CL}_{50} \mathrm{~S}\right)$. Devido ao modo de reprodução de B. phoenicis um ciclo de seleção foi suficiente para obter a linhagem $\mathrm{R}$ a partir da população BAR-1, fato confirmado pelo aumento significativo da razão de resistência e aumento do coeficiente angular.

Embora a ocorrência de falhas no controle de B. phoenicis tem sido pouco freqüientes, mas devido a confirmação da evolução da resistência do ácaro-da-leprose ao propargite, no presente trabalho, elas podem estar ligadas a resistência. As falhas no controle não ocorrem apenas devido a frequiência dos indivíduos resistentes, mas também podem estar relacionadas a densidade da praga, estrutura etária da população, ocorrência de inimigos naturais (ffrench-Constant \& Roush, 1990; Goodwin et al., 1995; Grafton-Cardwell et al., 1987; Welty et al., 1989), qualidade da pulverização e condições climáticas (Boggio, 1995; Violante Netto, 1987). A relação entre razão de resistência e ocorrência de falhas de controle no campo nem sempre são observadas. Nos Estados Unidos, o controle de ácaros tetraniquídeos proporcionado pelo propargite foi considerado satisfatório, embora uma linhagem de $T$. pacificus tinha apresentado uma razão de resistência de aproximadamente 24 vezes (Keena \& Granett, 1985). Segundo Goodwin et al. (1995), falhas no controle do ácaro T. urticae em rosas foram observadas em populações que apresentavam razão de resistência entre 87,8 e 135,5 vezes, baseada na CL95. Dessa maneira, os estudos de detecção da resistência devem ser iniciados antes que falhas no controle estejam relacionadas ao desenvolvimento da 


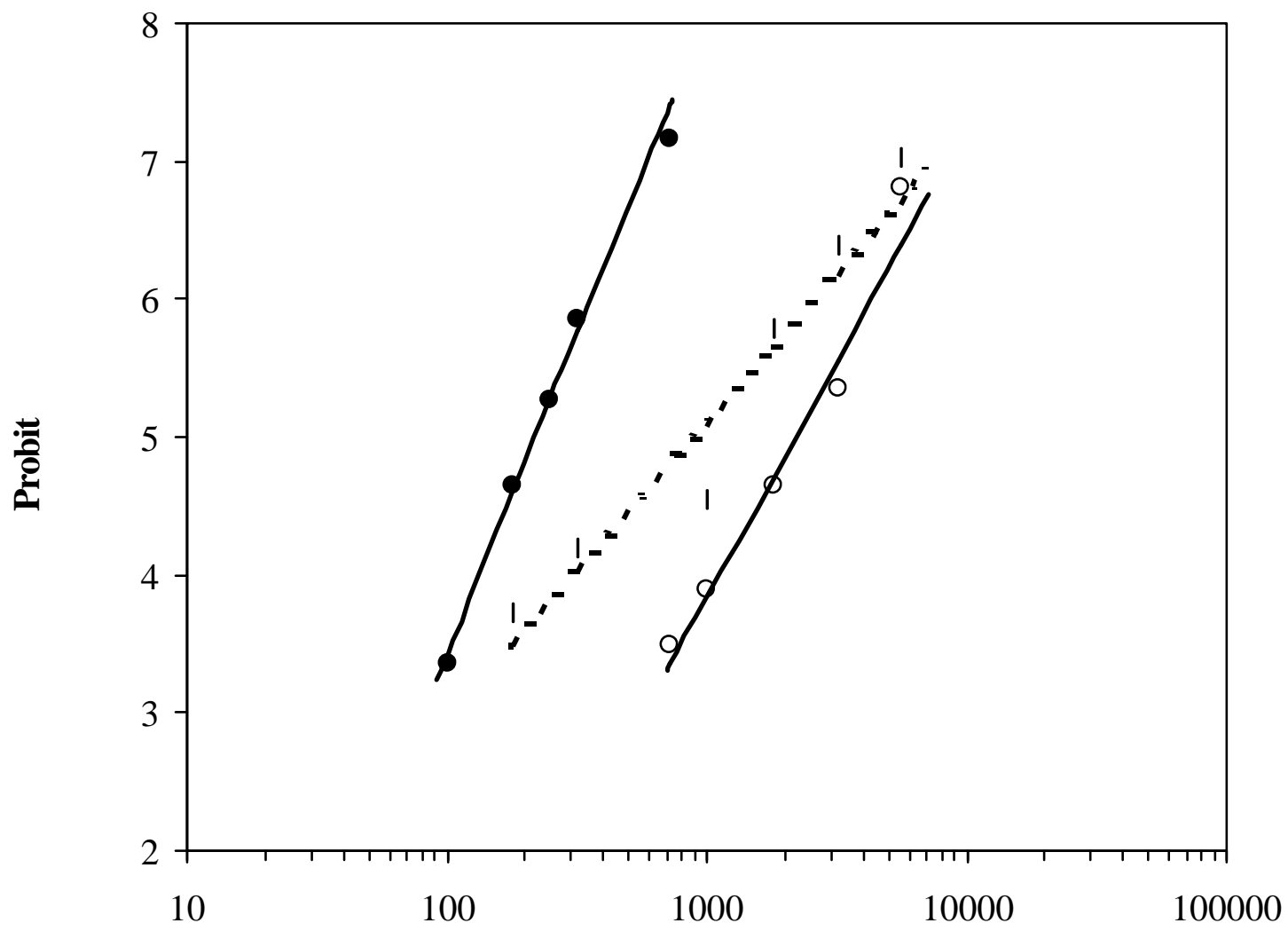

$\mu \mathrm{g}$ de propargite/ml de água

Figura 3 - Caracterização da resistência de Brevipalpus phoenicis ao propargite. Nesta figura encontram-se representadas a linhagem suscetível $(\mathrm{S})(\bullet)$, população BAR-1 $(\bullet)$ e linhagem resistente $(\mathrm{R})(\mathrm{O})$. 
resistência, ou seja, quando a freqüência de resistência ainda é baixa, para que seja implementado um programa de manejo da resistência preventivo (ffrench-Constant \& Roush, 1990). Entretanto, após a detecção da resistência podem ser realizados estudos para conhecer os principais fatores envolvidos na evolução da resistência, por exemplo, custo adaptativo, relação de resistência cruzada e mecanismos de resistência. Dessa forma, estes estudos poderão contribuir para aperfeiçoar as estratégias utilizadas no manejo da resistência de $B$. phoenicis em citros.

\subsection{Interação de Brevipalpus phoenicis, propargite e citros}

\subsubsection{Efeito do modo de exposição de Brevipalpus phoenicis ao propargite}

$\mathrm{O}$ resultado da discriminação entre as linhagens $\mathrm{S}$ e $\mathrm{R}$ de B. phoenicis ao propargite pelos bioensaios de contato residual e contato direto está apresentado na Tabela 4 e Figura 4. Pelo contato residual as hipóteses de igualdade e paralelismo das curvas de concentração-mortalidade das linhagens S e R foram rejeitadas $\left(\chi^{2}=914,43\right.$; g.l.= 2; $\mathrm{P}<0,05)$ e $\left(\chi^{2}=15,17 ;\right.$ g.l. $\left.=1 ; \mathrm{P}<0,05\right)$ e a razão de resistência foi de 10,09 vezes. Enquanto para o contato direto também não foi observada sobreposição dos intervalos de confiança das $\mathrm{CL}_{50}$, indicando que as curvas foram diferentes, confirmado pelo teste de igualdade e paralelismo que rejeitou a hipótese de igualdade das curvas $\chi^{2}=701,62$; g.l.= 2; $\mathrm{P}<0,05)$, mas aceitou a igualdade dos coeficientes angulares $\chi^{2}=0,89 ;$ g.l. $=1$; P>0,05), ou seja, as curvas foram paralelas. A razão de resistência foi de 7,46 vezes.

Foi verificada a sobreposição dos intervalos de confiança das CL50 das curvas toxicológicas da linhagem $\mathrm{S}$ pelo contato residual e direto, sugerindo que as curvas não foram diferentes, mas pelo teste de igualdade e paralelismo foi rejeitada a hipótese de igualdade entre as curvas $\left(\chi^{2}=7,32 ;\right.$ g.l. $\left.=2 ; \mathrm{P}<0,05\right)$, mas aceita a hipótese de

paralelismo $\left(\chi^{2}=1,51 ;\right.$ g.l.= $\left.1 ; \mathrm{P}>0,05\right)$. A mesma resposta foi observada para a linhagem $\mathrm{R} \chi^{2}=701,62 ;$ g.l.= $\left.2 ; \mathrm{P}<0,05\right)$ e $\left(\chi^{2}=0,89 ;\right.$ g.l.= $\left.1 ; \mathrm{P}>0,05\right)$ respectivamente. 
Tabela 4. Resultados da caracterização toxicológica da linhagem suscetível (S) e resistente (R) de Brevipalpus phoenicis ao propargite avaliada pelo bioensaio de contato residual e contato direto.

\begin{tabular}{|c|c|c|c|c|c|c|c|}
\hline Bioensaio & Linhagem & $\mathrm{n}^{\mathrm{a}}$ & $\begin{array}{c}\text { Coeficiente } \\
\text { Angular }( \pm \mathrm{EP})\end{array}$ & $\begin{array}{c}\mathrm{CL}_{50}(\mu \mathrm{g} \text { i.a./ml) } \\
(\mathrm{IC} 95 \%)\end{array}$ & $\chi^{2}$ & g.l. ${ }^{b}$ & $\mathrm{RR}^{\mathrm{c}}$ \\
\hline \multirow{3}{*}{$\begin{array}{l}\text { Contato } \\
\text { Residual }\end{array}$} & $\mathrm{S}$ & 1.087 & $4,64 \pm 0,28$ & 217,51 & 2,25 & 3 & - \\
\hline & & & & $(207,07-228,35)$ & & & \\
\hline & $\mathrm{R}$ & 1.089 & $3,40 \pm 0,18$ & $\begin{array}{c}2.195,43 \\
(1.759,23-2.808,21)\end{array}$ & 12,71 & 3 & 10,09 \\
\hline \multirow[t]{2}{*}{$\begin{array}{l}\text { Contato } \\
\text { Direto }\end{array}$} & $\mathrm{S}$ & 877 & $4,19 \pm 0,25$ & $\begin{array}{c}197,02 \\
(168,81-227,91)\end{array}$ & 2,32 & 2 & - \\
\hline & $\mathrm{R}$ & 1.062 & $3,88 \pm 0,21$ & $\begin{array}{c}1.469,89 \\
(1.215,93-1.771,82)\end{array}$ & 10,10 & 3 & 7,46 \\
\hline
\end{tabular}

\footnotetext{
${ }^{a}$ Número de ácaros testados

${ }^{\mathrm{b}}$ Graus de liberdade

${ }^{c}$ Razão de Resistência
}

Este resultado confirma a maior discriminação entre as linhagens $\mathrm{S}$ e $\mathrm{R}$ de B. phoenicis ao propargite pelo contato residual.

A menor discriminação causada pelo contato direto também foi observada em T. urticae ao dicofol e propargite (Dennehy et al., 1983; Dennehy et al., 1987) e em Phyllocoptruta oleivora (Ashmead) ao dicofol (Omoto et al., 1995). O bioensaio empregado em programas de manejo da resistência deve intensificar as diferenças entre as linhagens suscetível e resistente, isto é aumentar a razão de resistência e ou aumentar os coeficientes angulares das curvas toxicológicas. Entretanto, para o controle de artrópodes o oposto é desejado, ou seja, reduzir a discriminação entre as linhagens para obter máxima eficiência no controle, dessa maneira retardar a evolução da resistência (ffrench-Constant \& Roush, 1990). 


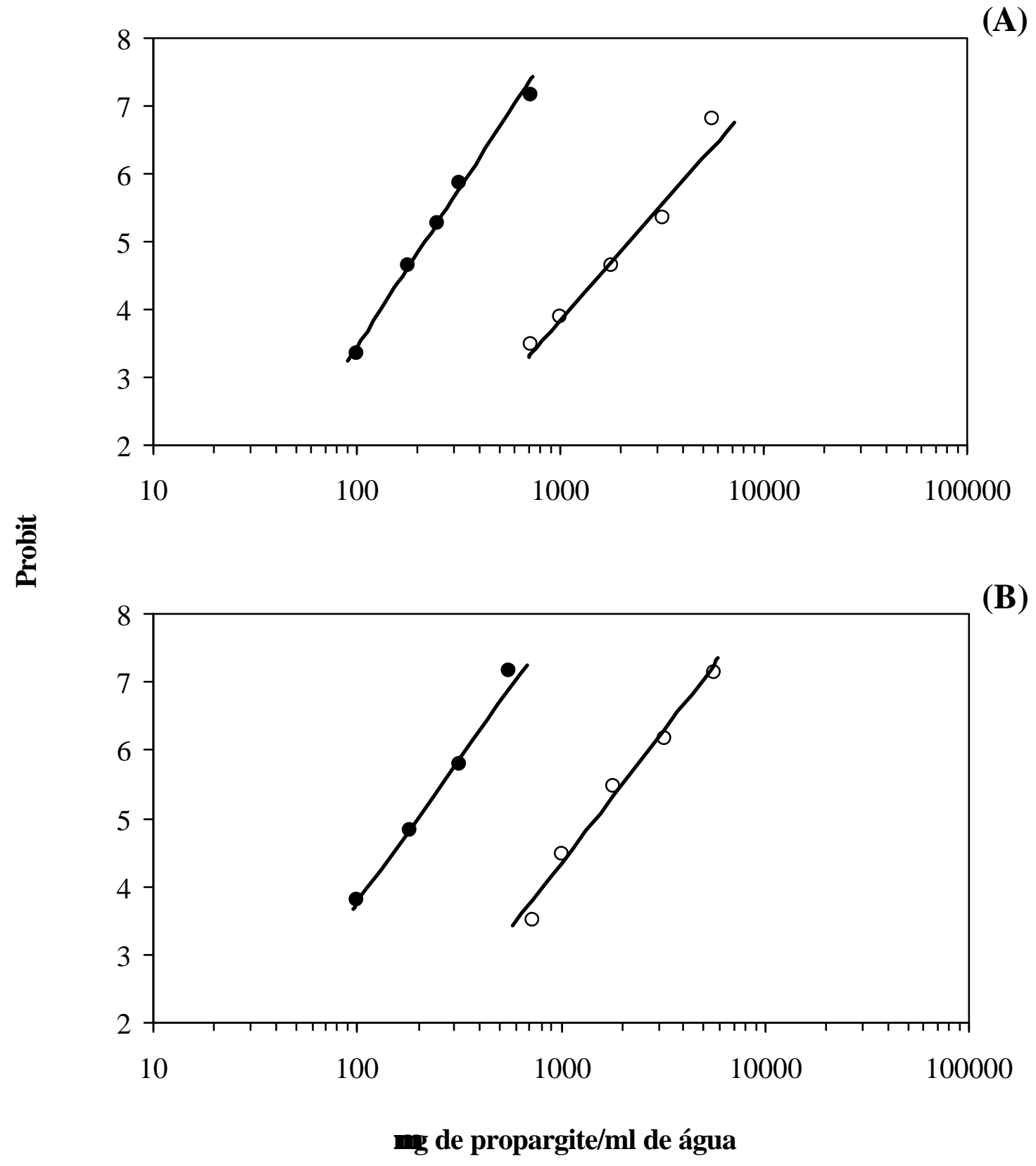

Figura 4 - Caracterização toxicológica das linhagens suscetível (S) (•) e resistente (R) (O) de Brevipalpus phoenicis ao propargite pelo contato residual (A) e contato direto (B). 


\subsubsection{Persistência da atividade biológica de propargite sobre Brevipalpus phoenicis}

O modelo de regressão binomial adequado para persistência da atividade biológica de propargite sobre B. phoenicis para os períodos de exposição de 24 e 48 h foram os modelos logísticos linear e cúbico respectivamente (Figura 5). O efeito das linhagens $\mathrm{S}$ e $\mathrm{R}$ de B. phoenicis foi significativo para os períodos de exposição de 24 (F= 147,09; g.l.= 1, 70; $\mathrm{P}<0,05)$ e 48 h $(\mathrm{F}=101,06 ;$ g.l.= 1, 70; $\mathrm{P}<0,05)$. O acréscimo do fator dias após aplicação no modelo logístico demonstrou também ser significativo para $24(\mathrm{~F}=58,92 ;$ g.l.= 1, 70; $\mathrm{P}<0,05)$ e 48 h $(\mathrm{F}=93,36 ;$ g.l.= 1, 70; $\mathrm{P}<0,05)$. Para os modelos logísticos propostos o acréscimo do efeito da interação entre linhagens e dias após aplicação, para verificar falta de ajuste do modelo, não foi significativo para 24 (F= 1,31; g.l.= 11, 70; P>0,05) e 48 h $(\mathrm{F}=1,23 ;$ g.l.= 9, 70; $\mathrm{P}>0,05)$ de exposição, indicando que as linhagens responderam de forma semelhante a diferenças de idade do resíduo, ou seja, as curvas foram paralelas.

A mortalidade $(+$ erro padrão da média) observada no período de exposição de 48 h para a linhagem $\mathrm{R}$ no $0,1,3$ e $5^{\circ}$ dia após aplicação foram $37,41( \pm 10,36) ; 65,52$ $( \pm 12,58) ; 42,58( \pm 8,11)$ e $11,71 \%( \pm 5,26)$, respectivamente, portanto mortalidade inferior a $50 \%$ foi observada a partir do $3^{0}$ dia após aplicação. Enquanto, para a linhagem $\mathrm{S}$ foram observadas mortalidade $(\uplus$ erro padrão da média) de $100 ; 100 ; 95,83$ $( \pm 3,27)$ e $78,48 \%( \pm 11,49)$ no mesmo período, respectivamente, sendo que mortalidade inferior a $50 \%$ foi verificada a partir do $10^{\circ}$ dia após aplicação. A ocorrência de chuvas foram verificadas a partir do final do 3,4 e $11^{\underline{0}}$ dia após aplicação. Possivelmente, as intempéries climáticas exerceram importante papel na degradação de pesticidas durante os primeiros dias após aplicação.

Segundo Alves et al. (2000b), o resíduo da pulverização do dicofol em citros resultou em mortalidade de B. phoenicis superior a 95\% até o 14ํㅜ dia após aplicação para a linhagem suscetível e para a linhagem resistente ao dicofol a mortalidade em nenhuma avaliação ultrapassou 10\%. Em pêssego foi observada mortalidade superior a $50 \%$ em Panonychus ulmi (Koch) proporcionada pelos acaricidas propargite, dicofol, clofentezina e hexitiazox até o 10, 15, 30 e 30ํำ dia após aplicação respectivamente. A 
(A)

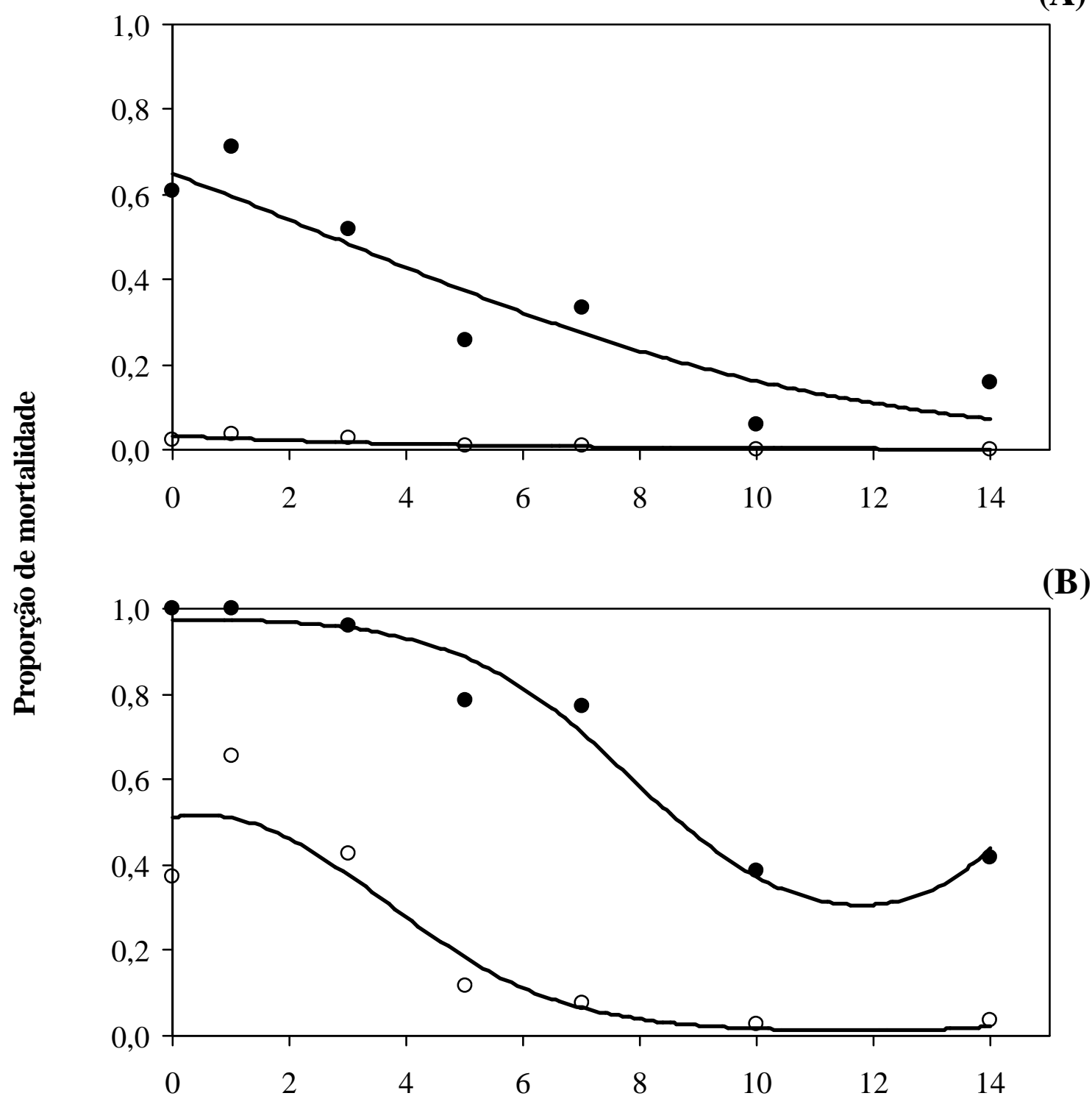

Dias após aplicação

Figura 5 - As curvas referem-se ao ajuste dos dados observados aos modelos logísticos linear e cúbico para as linhagens suscetível $(\mathrm{S})(\bullet)$ e resistente $(\mathrm{R})(\mathrm{O})$ de Brevipalpus phoenicis ao propargite para os períodos de exposição de 24 (A) e 48 horas (B). 
maior persistência biológica desses acaricidas comparada ao propargite foi sugerida como um importante fator no desenvolvimento da resistência em P. ulmi (Pree et al., 1992). Os pesticidas de baixa persistência biológica, geralmente, retardam a evolução da resistência em artrópodes (Georghiou, 1983; Tabashnik \& Croft, 1982; Taylor \& Georghiou, 1982; Taylor et al., 1983). Segundo Omoto et al. (1995), a curta atividade biológica do dicofol sobre o ácaro $P$. oleivora associado a presença de locais de refúgio, principalmente na própria planta de citros, são aspectos positivos para o manejo da resistência.

Para o manejo da resistência é fundamental a redução da pressão de seleção, podendo ser obtida pela utilização de produtos de curta atividade biológica, portanto a preservação da vida útil do propargite é importante para o manejo da resistência de $B$. phoenicis. Atualmente, o principal método de controle do ácaro-da-leprose tem sido o controle químico, dessa maneira as principais estratégias de manejo da resistência empregadas tem sido a mistura e rotação de acaricidas.

Os estudos da persistência biológica dos pesticidas são um dos parâmetros necessários para indicação do uso da mistura como estratégia de manejo da resistência porque os pesticidas devem apresentar atividades biológicas semelhantes (Georghiou, 1983). Além da detecção da resistência de B. phoenicis ao propargite no presente trabalho, casos de resistência foram confirmados para o dicofol (Omoto et al., 2000) e hexitiazox (Campos \& Omoto, 2002). A eficiência desses acaricidas em mistura pode ser comprometida por causa da diferença na persistência da atividade biológica (Pree et al., 1992) e por causa dos casos de resistência detectados em B. phoenicis. Na citricultura é comum a mistura entre acaricidas de ação adulticida e ovicida. Em termos de manejo da resistência pode não ser apropriada porque não controlam o mesmo estágio de desenvolvimento da praga, uma tez que o princípio da mistura consiste na eliminação dos indivíduos resistentes a um produto pelo outro produto e vice-versa, sobrevivendo apenas os resistentes a ambos os produtos que devem ocorrer em baixa frequiência (Georghiou, 1983). Uma vantagem econômica da mistura é a possibilidade da redução da dose dos pesticidas, mas esse procedimento deve ser adotado somente quando os pesticidas apresentarem efeito sinérgico (Georghiou, 1983). Assumindo que os produtos 
recomendados não apresentam sinergismo, então pelos resultados obtidos a redução da dose do propargite poderia ser ineficiente tanto no controle dos ácaros suscetíveis como dos resistentes. Portanto para recomendação da mistura é necessário conhecer a persistência biológica dos acaricidas, a suscetibilidade das populações, se há sinergismo e a relação de resistência cruzada entre os acaricidas recomendados na citricultura.

\subsection{Considerações finais}

O manejo da resistência deve estar inserido num contexto de manejo integrado de pragas e vice-versa (Georghiou, 1983). Dessa maneira, adoção de medidas não químicas devem ser estimuladas, por exemplo, evitar o atraso da colheita ou realizar colheitas desinfestante (Gravena, 1998), controle da verrugose e uso de pesticidas seletivos que auxiliam na redução populacional do ácaro-da-leprose em citros, consequentemente na redução da pressão de seleção exercida pelos acaricidas.

Para implementação de um programa de manejo da resistência de B. phoenicis a acaricidas a primeira etapa é a caracterização toxicológica da suscetibilidade. Nesse sentido concentrações diagnósticas ou discriminatórias foram definidas para o dicofol (Omoto et al., 2000), óxido de fembutatina, cihexatina (Konno et al., 2001), hexitiazox (Campos \& Omoto, 2002) e no presente trabalho para o propargite. Dessa maneira o monitoramento da suscetibilidade do ácaro-da-leprose aos principais grupos químicos de acaricidas utilizados na citricultura pode ser realizado. Pode-se enfatizar alguns objetivos com os estudos de detecção da resistência: primeiramente, a conscientização por parte dos agricultores, dos profissionais ligados a área fitossanitária, seja pública ou privada, e das empresas fabricantes dos defensivos agrícolas da magnitude da resistência no Brasil. Estes estudos servem como um ponto inicial para acompanhar a evolução da resistência do ácaro-da-leprose a acaricidas e proporcionarem subsídios para implementação de um programa de manejo da resistência de B. phoenicis na citricultura.

O desenvolvimento da resistência é influenciada por diversos fatores genéticos, biológicos e operacionais, sendo que após a caracterização da resistência pode-se estudar quais são os principais fatores envolvidos na resistência. Sendo assim outros estudos 
poderão ser realizados como por exemplo a estabilidade da resistência, custo adaptativo dos indivíduos resistentes e relação de resistência cruzada para aperfeiçoar as estratégias de manejo da resistência. Outro fator fundamental para o desenvolvimento da resistência do ácaro-da-leprose é conhecer a importância do seu modo de reprodução na composição genética das populações, isto é, esclarecer a funcionalidade dos ácaros machos. As técnicas moleculares constituem importantes ferramentas para averiguar diferenças genéticas entre populações e associadas a parâmetros biológicos, como suscetibilidade a acaricidas, podem auxiliar na compreensão da evolução da resistência em B. phoenicis. A migração também é responsável pelo aumento da variabilidade genética, sendo necessário estudar o seu impacto no desenvolvimento da resistência do ácaro-da-leprose. 


\section{CONCLUSÕES}

Há diferenças na suscetibilidade ao propargite nas populações de Brevipalpus phoenicis (Geijskes) coletadas em pomares comerciais de citros do Estado de São Paulo.

A razão de resistência de $B$. phoenicis ao propargite é de 10 vezes.

O modo de exposição de B. phoenicis ao propargite por contato residual proporciona maior discriminação do que por contato direto entre as linhagens suscetível e resistente.

A persistência da atividade biológica de propargite sobre frutos de citros é baixa em condições de campo e há discriminação entre as linhagens suscetível e resistente de B. phoenicis ao propargite. 
ANEXOS 
Anexo A - Os quadros das análises de variâncias referente ao monitoramento da suscetibilidade das populações de Brevipalpus phoenicis (Geijskes) ao propargite.

Análise de variância dos dados de sobrevivência de B. phoenicis da concentração diagnóstica de $320 \mu \mathrm{g}$ de propargite/ml de água.

\begin{tabular}{lccccc}
\hline Causas da variação & g.l. & Soma dos quadrados & Quadrados médio & F & P>F \\
\hline População & 13 & 3,556 & 0,273 & 15,66 & 0,0001 \\
Resíduo & 56 & 0,978 & 0,017 & & \\
Total & 69 & 4,534 & & & \\
\hline
\end{tabular}

Análise de variância dos dados de sobrevivência de B. phoenicis da concentração diagnóstica de $720 \mu \mathrm{g}$ de propargite/ml de água.

\begin{tabular}{lccccc}
\hline Causas da variação & g.l. & Soma dos quadrados & Quadrados médio & F & P>F \\
\hline População & 13 & 6,317 & 0,486 & 31,02 & 0,0001 \\
Resíduo & 56 & 0,877 & 0,016 & & \\
Total & 69 & 7,194 & & & \\
\hline
\end{tabular}

* Dados originais transformados em $\operatorname{arc} \operatorname{sen}(\sqrt{X})$ 
Anexo B - Os quadros das análises de deviance sequienciais referente a persistência da atividade biológica do propargite sobre $B$. phoenicis.

Análise de deviance sequiencial dos dados de mortalidade de $B$. phoenicis avaliadas após 24 horas de período de exposição.

\begin{tabular}{lcccc}
\hline Causas da variação & g.l. & Deviance & F & P>F \\
\hline Linhagem & 1 & 419,26 & 147,09 & $<2,2 \mathrm{e}-16$ \\
Dia & 1 & 167,95 & 58,92 & $7,211 \mathrm{e}-11$ \\
Linhagem x Dia & 11 & 41,01 & 1,31 & 0,2385 \\
(Falta de ajuste) & & & & \\
Resíduo & 70 & 218,23 & & \\
Total & 83 & 846,46 & & \\
\hline
\end{tabular}

Fator de heterogeneidade estimado: 2,850434

Análise de deviance seqüencial dos dados de mortalidade de B. phoenicis avaliada após 48 horas de período de exposição.

\begin{tabular}{lcccc}
\hline Causas da variação & g.l. & Deviance & F & P>F \\
\hline Linhagem & 1 & 475,86 & 101,06 & $3,210 \mathrm{e}-15$ \\
Dia & 1 & 439,63 & 93,36 & $1,632 \mathrm{e}-14$ \\
$\mathrm{Dia}^{2}$ & 1 & 16,08 & 3,41 & 0,068828 \\
$\mathrm{Dia}^{3}$ & 1 & 34,86 & 7,40 & 0,008205 \\
Linhagem x Dia & 9 & 51,97 & 1,2263 & 0,293352 \\
(Falta de ajuste) & & & & \\
Resíduo & 70 & 369,59 & & \\
Total & 83 & $1.388,00$ & & \\
\hline
\end{tabular}

Fator de heterogeneidade estimado: 4,708794 
Anexo C - As equações dos modelos de regressão binomial propostos para a persistência da atividade biológica do propargite sobre B. phoenicis.

Período de exposição de 24 horas

$$
\begin{aligned}
& \hat{\mathrm{p}}_{\mathrm{R}}(\mathrm{x})=\frac{\exp (-3,37323-0,22668 \mathrm{x})}{1+\exp (-3,37323-0,22668 \mathrm{x})} \\
& \hat{\mathrm{p}}_{\mathrm{S}}(\mathrm{x})=\frac{\exp (0,61579-0,22668 \mathrm{x})}{1+\exp (0,61579-0,22668 \mathrm{x})}
\end{aligned}
$$

Período de exposição de 48 horas

$$
\begin{aligned}
& \hat{\mathrm{p}}_{\mathrm{R}}(\mathrm{x})=\frac{\exp \left(0,044589+0,10709 \mathrm{x}-0,112718 \mathrm{x}^{2}+0,006135 \mathrm{x}^{3}\right)}{1+\exp \left(0,044589+0,10709 \mathrm{x}-0,112718 \mathrm{x}^{2}+0,006135 \mathrm{x}^{3}\right)} \\
& \hat{\mathrm{p}}_{\mathrm{S}}(\mathrm{x})=\frac{\exp \left(3,594465+0,10709 \mathrm{x}-0,112718 \mathrm{x}^{2}+0,006135 \mathrm{x}^{3}\right)}{1+\exp \left(3,594465+0,10709 \mathrm{x}-0,112718 \mathrm{x}^{2}+0,006135 \mathrm{x}^{3}\right)}
\end{aligned}
$$

sendo: $\hat{\mathrm{p}}_{\mathrm{R}}$ e $\hat{\mathrm{p}}_{\mathrm{S}}$ a proporção esperada de mortos para as linhagens resistente $(\mathrm{R}) \mathrm{e}$ suscetível (S) de B. phoenicis, respectivamente, e x o número de dias após a aplicação do propargite. 


\section{REFERÊNCIAS BIBLIOGRÁFICAS}

ALVES, E.B. Manejo da resistência do ácaro da leprose Brevipalpus phoenicis (Geijskes, 1939) (Acari: Tenuipalpidae) ao acaricida dicofol. Piracicaba, 1999. 91p. Dissertação (Mestrado) - Escola Superior de Agricultura "Luiz de Queiroz", Universidade de São Paulo.

ALVES, E.B.; CASARIN, N.F.B.; OMOTO, C. Mecanismos de dispersão de Brevipalpus phoenicis (Geijskes, 1939) (Acari: Tenuipalpidae) em citros. In: CONGRESSO BRASILEIRO DE ENTOMOLOGIA, 19., Manaus, 2002. Resumos. Manaus:INPA, 2002. p.247.

ALVES, E.B.; OMOTO, C.; FRANCO, C.R. Mistura de dicofol com fempiroximato no manejo da resistência de Brevipalpus phoenicis (Geijskes) (Acari: Tenuipalpidae) ao dicofol. Anais da Sociedade Entomológica do Brasil, v.29, n.4, p.789-797, 2000b.

ALVES, E.B.; OMOTO, C.; FRANCO, C.R. Resistência cruzada entre o dicofol e outros acaricidas em Brevipalpus phoenicis (Geijskes) (Acari: Tenuipalpidae). Anais da Sociedade Entomológica do Brasil, v.29, n.4, p.765-771, 2000a.

BOGGIO, A.M. Aspectos gerais sobre a aplicação de defensivos em citros. In: OLIVEIRA, C.A.L.; DONADIO, L.C. (Ed.). Leprose dos citros. Jaboticabal: FUNEP, 1995. p.129-136. 
CAMPOS, F.J.; OMOTO, C. Resistance to hexythiazox in Brevipalpus phoenicis (Acari: Tenuipalpidae) from Brazilian citrus. Experimental and Applied Acarology, v.26, n.3/4, p.243-251, 2002.

CASIDA, J.E.; QUISTAD, G.B. Golden age of insecticide research: past, present, or future?. Annual Review of Entomology, v.43, p.1-16, 1998.

CHAGAS, C.M. Associação do ácaro Brevipalpus phoenicis (Geijskes) à mancha anular do cafeeiro. O Biológico, v.39, p.229-232, 1973.

CHAPMAN, R.B.; PENMAN, D.R. Resistance to propargite by European red mite and two-spotted mite. New Zealand Journal of Agricultural Research, v.27, p.103105, 1984.

CHIAVEGATO, L.G. Biologia do ácaro Brevipalpus phoenicis em citros. Pesquisa Agropecuária Brasileira, v.21, n.8, p.813-816, 1986.

CHIAVEGATO, L.G. A leprose dos citros no Estado de São Paulo. Laranja, v.8, n.1, p.7-18, 1987.

CHIAVEGATO, L.G.; MISCHAN, N.M. Comportamento do ácaro Brevipalpus phoenicis (Geijskes, 1939) (Acari: Tenuipalpidae) em frutos de diferentes variedades cítricas. Científica, v.15, n.1/2, p.17-22, 1987.

CHILDERS, C.C.; KITAJIMA, E.W.; WELBOURN, W.C.; RIVERA, C.; OCHOA, R. Brevipalpus mites on citrus and their status as vectors of citrus leprosis. Manejo Integrado de Plagas, v.60, p.66-70, 2001. 
COMENAlE NETO, C.; YAMAMOTO, P.T.; GRAVENA, S.; SILVA, B.B. Período de controle do ácaro da leprose Brevipalpus phoenicis por acaricidas em diferentes níveis de infestação. Laranja, v.16, n.2, p.251-161, 1995.

COMPTON, C.C.; KEARNS, C.W. Improved control of Red Spider on greenhouse crops with sulfur and cyclohexylamine derivatives. Journal of Economic Entomology, v.30, n.3, p.512-522, 1937.

CORBETT, J.R.; WRIGHT, K.; BAILLIE, A.C. The biochemical mode of action of pesticides. London: Academic Press, 1984. 382p.

CROFT, B.A.; VAN DE BANN, H.E. Ecological end genetic factors influencing evolution of pesticide resistance in tetranychid and phytoseiid mites. Experimental \& Applied Acarology, v.4, n.3, p.277-300, 1988.

CROW, J. Genetics of insect resistance to chemicals. Annual Review of Entomology, v.2, p.227-246, 1957.

DENNEHY, T.J.; GRANETT, J.; LEIGH, T.F. Relevance of Slide-dip and Residual bioassay comparisons to detection of resistance in Spider mites. Journal of Economic Entomology, v.76, p.1225-1230, 1983.

DENNEHY, T.J.; GRANETT, J.; LEIGH, T.F.; COLVIN, A. Laboratory and field investigations of spider mite (Acari: Tetranychidae) resistance to the selective acaricide propargite. Journal of Economic Entomology, v.80, n.3, p.565-574, 1987.

FERGUNSSON-KOLMES, L.A.; SCOTT, J.G.; DENNEHY, T.J. Dicofol resistance in Tetranychus urticae (Acari: Tetranychidae): cross-resistance and pharmacokinetics. Journal of Economic Entomology, v.84, n.1, p.41-48, 1991. 
FFRENCH-CONSTANT, R.H.; ROUSH, R.T. Resistance detection and documentation:

The relative roles of pesticidal and biochemical assays. In: ROUSH, R.T.; TABASHNIK, B.E. (Ed.). Pesticide resistance in arthropods. New York: Chapman and Hall, 1990. cap.2, p. 4-48.

FLECHTMANN, C.H.W. Ácaros de importância agrícola. São Paulo: Nobel, 1977. $150 \mathrm{p}$.

FNP CONSULTORIA \& COMÉRCIO. Agrianual 2002: anuário da agricultura brasileira. São Paulo, 2002. p.302-315: Citros: Laranja.

GEORGHIOU, G.P. Management of resistance in arthropods. In: GEORGHIOU, G.P.; SAITO, T. (Ed.). Pest resistance to pesticides. New York: Plenum, 1983. p.769792.

GEORGHIOU, G.P. The magnitude of the resistance problem. In: NATIONAL RESEARCH COUNCIL. Pesticide resistance: strategies and tactics for management. Washington, D.C.: National Academic Press, 1986. cap.1, p.14-43.

GEORGHIOU, G.P.; MELLON, R.B. Pesticide resistance in time and space. In: GEORGHIOU, G.P.; SAITO, T. Pest resistance to pesticides. New York: Plenum Press, 1983. p.1-46.

GEORGHIOU, G.P.; TAYLOR, C.E. Genetic and Biological influences in the evolution of insecticide resistance. Journal of Economic Entomology, v.70, n.3, p.319-323, 1977a.

GEORGHIOU, G.P.; TAYLOR, C.E. Operational influences in the evolution of insecticide resistance. Journal of Economic Entomology, v.70, n.5, p.653-658, 1977b. 
GEORGHIOU, G.P.; TAYLOR, C.E. Factors influencing the evolution of resistance. In: NATIONAL RESEARCH COUNCIL. Pesticide resistance: strategies and tactics for management. Washington, D.C.: National Academic Press, 1986. cap.3, p.157-169.

GEORGHIOU, G.P.; TEJADA, C.E. The ocurrence of resistance to pesticides in arthropods. Rome: FAO, 1991. 318p.

GOODWIN, S.; HERRON, G.; GOUGH, N.; WELlHAM, T.; ROPHAIL, J.; PARKER, R. Relationship between insecticide-acaricide resistance and field control in Tetranychus urticae (Acari: Tetranychidae) infesting roses. Journal of Economic Entomology, v.88, n.5, p.1106-1112, 1995.

GRAFTON-CARDWELL, E.E.; GRANETT, J.; LEIGH, T.F. Spider mites species (Acari: Tetranychidae) response to propargite: basis for an acaricide resistance management program. Journal of Economic Entomology, v.80, n.3, p.579-587, 1987.

GRAVENA, S. Manejo ecológico de pragas dos citros - aspectos práticos. Laranja, v.19, n.1, p.61-77, 1998.

GROETERS, F.R.; TABASHNIK, B.E. Roles of selection intensity, major genes, e minor genes in evolution of insecticide resistance. Journal of Economic Entomology, v.93, n.6, p.1580-1587, 2000.

GROSSCURT, A.C.; WIXLEY, R.A.J.; HAAR, M. ter. Cross-resistance between flucycloxuron, clofentezine and hexythiazox in Panonychus ulmi (fruit tree red spider mite). Experimental \& Applied Acarology, v.18, p.445-458, 1994. 
GUIRADO, N.; SILVERIO, J.L. Leprose e declínio: problemas sérios da citricultura paulista. Laranja, v.13, n.2, p.541-552, 1992.

HALLIDAY, W.R.; BURNHAM, K.P. Choosing the optimal diagnostic dose for monitoring insecticide resistance. Journal of Economic Entomology, v.83, n.4, p.1151-1159, 1990.

HARAMOTO, F.H. Biology and control of Brevipalpus poenicis (Geijskes) (Acarina: Tenuipalpidae). Hawaii Agricultural Experimental Station Technical Bulletin, n.68, p.1-60, 1969.

HELlE, W.; BOLlAND, H.R.; HEITMANS, W.R. Chromosomes and types of parthenogenesis in the false spider mites (Acari: Tenuipalpidae). Genetica, v.54, n.1, p.45-50, 1980.

HERRON, G.A.; ROPHAIL, J.; WILSON, L.J. The development of bifenthrin resistance in two-spotted spider mite (Acari: Tetranychidae) from Australian cotton. Experimental and Applied Acarology, v.25, p.301-310, 2001.

HOSKINS, W.M.; GORDON, H.T. Arthropod resistance to chemicals. Annual Review of Entomology, v.1, p.89-122, 1956.

HOY, M.A.; CONLEY, J. Propargite resistance in Pacific spider mite (Acari: Tetranychidae): stability and mode of inheritance. Journal of Economic Entomology, v.82, n.1, p.11-16, 1989.

HOY, M.A.; CONLEY, J.; ROBINSON, W. Cyhexatin and fenbutatin-oxide resistance in pacific spider mite (Acari: Tetranychidae): stability and mode of inheritance. Journal of Economic Entomology, v.81, n.1, p.57-64, 1988. 
HOYT, S.C.; WESTIGARD, P.H.; CROFT, B.A. Cyhexatin resistance in Oregon populations of Tetranychus urticae (Acarina: Tetranychidae). Journal of Economic Entomology, v.78, n.3, p.656-659, 1985.

JEPPSON, L.R.; WESTLAKE, W.E.; GUNTHER, F.A. Toxicity, control, and residue studies with DO-14 (2-(p-tert-butylphenoxy) ciclohexyl 2-propynyl sulfite) as an acaricide against the citrus red mite. Journal of Economic Entomology, v.62, n.3, p.531-536, 1969.

KABIR, K.H.; CHAPMAN, R.B.; PENMAN, D.R. Miticide bioassays with spider mites (Acari: Tetranychidae): effect of test method, exposure period and mortality criterion on the precision of response estimates. Experimental \& Applied Acarology, v.17, p.695-708, 1993.

KADIR, H.A.; KNOWLES, C.O. Inhibition of ATP dephosphorylation by acaricides with emphasis on the anti-ATPase activity of the carbodiimide metabolite of diafenthiuron. Journal of Economic Entomology, v.84, n.3, p.801-805, 1991.

KEENA, M.A.; GRANETT, J. Variability in toxicity of propargite to spider mites (Acari: Tetranychidae) from California almonds. Journal of Economic Entomology, v.78, n.6, p.1212-1216, 1985.

KEENA, M.A.; GRANETT, J. Cyhexatin and propargite resistance in populations of Spider Mites (Acari: Tetranychidae) from California almonds. Journal of Economic Entomology, v.80, n.3, p.560-564, 1987.

KEENA, M.A.; GRANETT, J. Genetic analysis of propargite resistance in Pacific spider mites and Twospotted spider mites (Acari: Tetranychidae). Journal of Economic Entomology, v.83, n.3, p.655-661, 1990. 
KITAJIMA, E.W.; MÜLLER, G.W.; COSTA, A.S.; YUKI, V.A. Short, rod-like particles asspciated with citrus leprosis, Virology, v.50, n.1, p.254-258, 1972.

KITAJIMA, E.W.; REZENDE, J.A.M.; RODRIGUES, J.C.V.; CHIAVEGATO, L.G.; PIZA JR., C.T.; MOROZINI, W. Green Spot of passion fruit, a possible viral disease associated with infestation by the mite Brevipalpus phoenicis. Fitopatologia Brasileira, v.22, n.4, p.555-559, 1997.

KONNO, R.H.; FRANCO, C.R.; OMOTO, C. Suscetibilidade de populações de Brevipalpus phoenicis (Geijskes, 1939) (Acari: Tenuipalpidae) a acaricidas organoestânicos em citros. Scientia Agricola, v.58, n.4, p.703-709, 2001.

LAL, L. Biology of Brevipalpus phoenicis (Geijskes) (Tenuipalpidae: Acarina). Acarologia, v.20, n.1, p.97-101, 1978.

LEORA SOFTWARE. Polo-PC: a user's guide to probit or logit analysis. Berkeley, 1987. 20p.

MAIA, O.M.A.; OLIVEIRA, C.A.L. Capacidade de colonização de Brevipalpus phoenicis (Geijskes, 1939) (Acari: Tenuipalpidae) em cercas vivas, quebra-ventos e plantas daninhas. In: CONGRESSO BRASILEIRO DE ENTOMOLOGIA, 19., Manaus, 2002. Resumos. Manaus:INPA, 2002a. p.249.

MAIA, O.M.A.; OLIVEIRA, C.A.L. Transmissibilidade do vírus da leprose das cercas vivas, quebra-ventos e plantas daninhas para citros através de B. phoenicis (Geijskes, 1939) (Acari: Tenuipalpidae). In: CONGRESSO BRASILEIRO DE ENTOMOLOGIA, 19., Manaus, 2002. Resumos. Manaus:INPA, 2002b. p.249. 
MANSOUR, F.A.; PLAUT, H.N. The effectiveness of various acaricides against resistant and susceptible carmine spider mites. Phytoparasitica, v.7, n.3, p.185-193, 1979.

MARTINELLI, N.M.; OLIVEIRA, C.A.L.; PERECIN, D. Conhecimentos básicos para estudos que envolvam levantamentos da população do ácaro Brevipalpus phoenicis (Geijskes, 1939) na cultura do citrus. Científica, v.4, n.3, p.242-253, 1976.

MCKENZIE, J.A.; WHITTEN, M.J.; ADENA, M.A. The effect of genetic background on the fitness of diazinon resistance genotypes of the Australian Sheep Blowfly, Lucilia cuprina. Heredity, v.49, n.1, p.1-9, 1982.

MUSUMECI, M.R.; ROSSETTI, V. Transmissão dos sintomas da leprose dos citros pelo ácaro Brevipalpus phoenicis. Ciência e Cultura, v.15, n.3, p.228, 1963.

MYAZAKI, I.; SUPLICY FILHO, N; SAMPAIO, A.S. O Biológico, v.48, n.1, p.2124, 1982.

NAKANO, O. Rotatividade de ingredientes ativos em citros. In: OLIVEIRA, C.A.L.; DONADIO, L.C. (Ed.). Leprose dos citros. Jaboticabal: Funep, 1995. p.189-194.

NAKANO, O.; SANCHES, G.A.; ISHIDA, A.K. Redução na infestação do ácaro da leprose Brevipalpus phoenicis (Geijskes, 1939) em citros através do controle da verrugose. Laranja, v.8, p.19-33, 1987.

NEVES, E.M.; DRAGONE, D.S.; DAYOUB, M. Demanda por defensivos na citricultura: análise comparativa com outras culturas comerciais. Laranja, v.22, n.2, p.285-297, 2001 b. 
NEVES, E.M.; DAYOUB, M.; DRAGONE, D.S.; NEVES, M.F. Citricultura brasileira: efeitos econômicos-financeiros, 1996-2000. Revista Brasileira de Fruticultura, v.23, n.2, p.432-436, 2001a.

OLIVEIRA, C.A.L. Flutuação populacional e medidas de controle do ácaro da leprose Brevipalpus phoenicis (Geijskes, 1939) em citros. Laranja, v.7, p.1-31, nov. 1986.

OLIVEIRA, C.A.L. Aspectos ecológicos de Brevipalpus phoenicis. In: OLIVEIRA, C.A.L.; DONADIO, L.C. (Ed.). Leprose dos citros. Jaboticabal: Funep, 1995. p.37-48.

OMOTO, C. Manejo da resistência de ácaros e insetos aos produtos químicos na citricultura. Laranja, v.16, n.1, p.187-208, 1995.

OMOTO, C. Acaricide resistance management of Leprosis mite (Brevipalpus phoenicis) in Brazilian citrus. Pesticide Science, v.52, p.189-198, 1998.

OMOTO, C.; ALVES, E.B.; RIBEIRO, P.C. Detecção e Monitoramento da resistência de Brevipalpus phoenicis (Geijskes) (Acari: Tenuipalpidae) ao dicofol. Anais da Sociedade Entomológica do Brasil, v.29, n.4, p.757-764, 2000.

OMOTO, C.; DENNEHY, T.J.; MCCOY, C.W.; CRANE, S.E.; LONG, J.W. Interface between citrus rust mite (Acari: Eriophyidae) and dicofol: implications for resistance management. Journal of Economic Entomology, v.88, n.5, p.1129-1137, 1995.

PIJNACKER, L.P.; FERWERDA, M.A.; BOLLAND, H.R.; HELLE, W. Haploid female parthenogenesis in the false spider mite Brevipalpus obovatus (Acari: Tenuipalpidae). Genetica, v.51, n.3, p.211-214, 1980. 
POLETTI, M. Variabilidades inter e intraespecífica na suscetibilidade de ácaros fitoseídeos (Acari: Phytoseiidae) a dicofol e deltametrina em citros. Piracicaba, 2002. 78p. Dissertação (Mestrado) - Escola Superior de Agricultura "Luiz de Queiroz", Universidade de São Paulo.

PREE, D.J.; MARSHALL, D.B.; MCGARVEY, B.D. Residual toxicity of dicofol, formetanate $\mathrm{HCl}$, propargite, hexythiazox, e clofentezine to European red mite on peach. The Canadian Entomology, v.124, p.59-67, Jan./Feb. 1992.

RAGA, A.; SATO, M.E.; CERÁVOLO, L.C.; ROSSI, A.C. Efeito de acaricidas sobre o ácaro da leprose Brevipalpus phoenicis (Geijskes) e ácaros predadores em plantas cítricas. Arquivos do Instituto Biológico, v.64, n.2, p.57-62, 1997.

RAGA, A.; SOUZA FILHO, M.F.; SATO, M.E.; GARCIA JÚNIOR, A. Avaliação de acaricidas contra o ácaro da leprose Brevipalpus phoenicis (Geijskes, 1939) em pomar cítrico de Neves Paulista. Arquivos do Instituto Biológico, v.63, n.1, p.2530, 1996.

REIS, P.R.; SOUZA, E.O.; ALVES, E.B. Seletividade de produtos fitossanitários ao ácaro predador Euseius alatus DeLeon (Acari: Phytoseiidae). Revista Brasileira de Fruticultura, v.21, n.3, p.350-355, 1999.

REIS, P.R.; CHIAVEGATO, L.G.; MORAES, G.J.; ALVES, E.B.; SOUZA, E.O. Seletividade de Agroquímicos ao ácaro predador Iphiseiodes zuluagai Denmark \& Muma (Acari: Phytoseiidae). Anais da Sociedade Entomológica do Brasil, v.27, n.2, p.265-274, 1998. 
RODRIGUES, J.C.V.; NOGUEIRA, N.L. Ocorrência de Brevipalpus phoenicis G (Acari: Tenuipalpidae) em Ligustrum lucidum (Oleraceae) associado à mancha anelar do ligustre. Anais da Sociedade Entomológica do Brasil, v.25, n.2, p.343344, 1996.

RODRIGUES, J.C.V.; NOGUEIRA, N.L.; FREITAS, D.S.; PRATES, H.S. Vírus-like particles associated with Brevipalpus phoenicis (Geijskes, 1939) (Acari: Tenuipalpidae), vector of citrus leprosis virus. Anais da Sociedade Entomológica do Brasil, v.26, n.2, p.391-395, 1997.

RODRIGUES, J.C.V.; CHILDERS, C.C.; KITAJIMA, E.W.; MACHADO, M.A.; NOGUEIRA, N.L. Uma estratégia para o controle da leprose dos citros. Laranja, v.22, n.2, p.411-423, 2001.

ROSSETTI, V.; FASSA, T.G.; MUSUMECI, R.M. Um novo ácaro dos laranjais paulistas. O Biológico, v.25, p.273-275, 1959.

ROSSETTI, V.; NAKADAIRA, J.T.; CALZA, R.; MIRANDA, C.A.B. A propagação da clorose zonada dos citrus pelo ácaro Brevipalpus phoenicis. O Biológico, v.31, p.113-116, 1965.

ROUSH, R.T. Designing resistance management programs: How can you choose? Pesticide Science, v.26, p.423-441, 1989.

ROUSH, R.T.; CROFT, B.A. Experimental population genetics and ecological studies of pesticide resistance in insects and mites. In: NATIONAL RESEARCH COUNCIL. Pesticide resistance: strategies and tactics for management. Washington, D.C.: National Academic Press, 1986. cap.3, p.257-270. 
ROUSH, R.T.; MCKENZIE, J.A. Ecological genetics of insecticide and acaricide resistance. Annual Review of Entomology, v.32, p.361-380, 1987.

ROUSH, R.T.; MILLER, G.L. Considerations for Design of Insecticide resistance monitoring Programs. Journal of Economic Entomology, v.79, p.293-298, 1986.

SALVO FILHO, A. Notas sobre o tratamento fitossanitários em citros. Laranja, v.18, p.155-163, 1997.

SATO, M.E.; RAGA, A. Ácaro da leprose. O Biológico, v.60, n.1, p.61-69, 1998.

SATO, M.E; SILVA, M. Seleções artificiais para resistência e suscetibilidade de Tetranychus urticae Koch (Acari: Tetranychidae) a propargite em laboratório. Arquivos do Instituto Biológico, v.69, p.258-260, 2002.

SATO, M.E.; SUPLICY FILHO, N.; SOUZA FILHO, M.F.S.; TAKEMATSU, A.P. Resistência do ácaro rajado Tetranychus urticae (Koch, 1836) (Acari: Tetranychidae) a diversos acaricidas em morangueiro (Fragaria sp) nos municípios de Atibaia-SP e Piedade-SP. Ecossistema, v.19, p.40-46, 1994a.

SATO, M.E.; RAGA, A.; CERÁVOLO, L.C.; CEZÁRIO, A.C.; ROSSI, A.C. Efeito da utilização de acaricidas em citros, sobre a população de Brevipalpus phoenicis (Geijskes, 1939) e ácaros predadores (Phytoseiidae). Scientia Agricola, v.52, n.2, p.282-286, 1995.

SATO, M.E.; RAGA, A.; CERÁVOLO, L.C.; ROSSI, A.C; CEZÁRIO, A.C. Efeito de acaricidas sobre Brevipalpus phoenicis (Geijskes, 1939) (Acari: Tenuipalpidae) e ácaros predadores (Família Phytoseiidae) em citros. Revista Brasileira de Fruticultura, v.14, n.2, p.87-93, 1992. 
SATO, M.E.; RAGA, A.; CERÁVOLO, L.C.; ROSSI, A.C.; POTENZA, M.R. Ácaros predadores em pomar cítrico de Presidente Prudente, estado de São Paulo. Anais da Sociedade Entomológica do Brasil, v.23, n.3, p.435-441, 1994b.

SATO, M.E.; RAGA, A.; CERÁVOLO, L.C.; ROSSI, A.C.; POTENZA, M.R. Efeito de acaricidas sobre o ácaro-da-leprose Brevipalpus phoenicis (Geijskes, 1939) (Acari: Tenuipalpidae) e sobre a fauna de artrópodos em citros. Arquivos do Instituto Biológico, v.61, n.1/2, p.9-15, 1994c.

SATO, M.E.; RAGA, A.; CERÁVOLO, L.C.; ROSSI, A.C.; SOUZA FILHO, M.F. Toxicidade residual de acaricidas a Iphiseiodes zuluagai Denmark \& Muma, 1972 (Acari: Phytoseiidae). Arquivos do Instituto Biológico, v.63, n.1, p.15-19, 1996.

SHEN, H. Resistance and cross-resistance of Tetranychus viennensis (Acari: Tetranychidae) to 14 inseticides and acaricides. Systematic and Applied Acarology, v.4, p.9-14, 1999.

SOUZA FILHO, M.F.; SUPLICY FILHO, N.; SATO, M.E.; TAKEMATSU, A.P. Suscetibilidade do ácaro-rajado proveniente de videira de Pilar do Sul, SP, a diversos acaricidas. Pesquisa Agropecuária Brasileira, v.29, n.8, p.1187-1192, 1994.

STUMPF, N.; NAUEN, R. Cross resistance, inheritance, and biochemistry of mitochondrial electron transport inhibitor-acaricide resistance in Tetranychus urticae (Acari: Tetranychidae). Journal of Economic Entomology, v.94, n.6, p.1577-1583, 2001.

SUPLICY FILHO, N.; SOUZA FILHO, M.F.; TAKEMATSU, A.P.; SATO, M.E. Resistência do ácaro rajado Tetranychus urticae (Koch) a acaricidas em roseira, na região de Itapevi, SP. Anais da Sociedade Entomológica do Brasil, v.23, n.1, p.51-55, 1994. 
SUPLICY FILHO, N.; CINTRA, A.F.; MYAZAKI, I.; OLIVEIRA, D.A.; TÉOFILO SOBRINHO, J. Comportamento do "ácaro da leprose" Brevipalpus phoenicis (Geijskes, 1939) em relação a alguns acaricidas na zona de Limeira. O Biológico, v.43, p.21-24, 1977.

TABASHNIK, B.E.; CROFT, B.A. Managing pesticide resistance in crop-arthropod complexes: interactions between biological and operational factors. Environmental Entomology, v.11, n.6, p.1137-1144, 1982.

TAKEMATSU, A.P.; SUPLICY FILHO, N.; SOUZA FILHO, M.F.; SATO, M.E. Sensibilidade de Tetranychus urticae (Koch, 1836), proveniente de roseira (Rosa sp.) de Holambra-SP, a alguns acaricidas. Revista de Agricultura, v.69, n.2, p.129-137, 1994.

TAYLOR, C.E.; GEORGHIOU, G.P. Influence of pesticide persistence in evolution of resistance. Environmental Entomology, v.11, n.3, p.746-750, 1982.

TAYLOR, C.E.; QUAGLIA, F.; GEORGHIOU, G.P. Evolution of resistance to insecticides: a cage study on the influence of migration and insecticide decay rates. Journal of Economic Entomology, v.76, p.704-707, 1983.

TRINDADE, M.L.B.; CHIAVEGATO, L.G. Colonização por Brevipalpus obovatus Donnadieu, 1875, Brevipalpus californicus (Banks, 1904) e Brevipalpus phoenicis (Geijskes, 1935) (Acari: Tenuipalpidae) em variedades cítricas. Laranja, v.11, n.1, p.227-240, 1990.

TRINDADE, M.L.B.; CHIAVEGATO, L.G. Caracterização biológica dos ácaros Brevipalpus obovatus D., B. californicus B. e B. phoenicis G. (Acari: Tenuipalpidae). Anais da Sociedade Entomológica do Brasil, v.23, n.2, p.189-195, 1994. 
UNWIN, B. Chemical resistance in populations of Tetranychus urticae (Koch) (Acarina: Tetranychidae) from apple orchards in New South Wales, Australia. Journal of the Australian Entomological Society, v.12, p.59-67, 1973.

VIOLANTE NETTO, A. Causas do insucesso no controle dos ácaros dos pomares de citros. Laranja, v.1, n.8, p.51-59, 1987.

WARE, G.W. Fundamentals of pesticides: a self-instruction guide. Fresno: Thomson Publ., 1991. 307p.

WEEKS, A.R.; MAREC, F.; BREEUWER, J.A.J. A mite species that consists entirely of haploid females. Science, v.292, p.2479-2482, Jun. 2001.

WEEKS, A.R.; VAN OPIJNEN, T.; BREEUWER, J.A.J. AFLP fingerprinting for assessing intraspecific variation and genome mapping in mites. Experimental and Applied Acarology, v.24, p.775-793, 2000.

WELTY, C.; REISSIG, W.H.; DENNEHY, T.J.; WEIRES, R.W. Activity of clofentezine against European Red Mite (Acari: Tetranychidae). Journal of Economic Entomology, v.82, n.1, p.197-203, 1989. 